\title{
Can adherence to dietary guidelines address excess caloric intake? An empirical assessment for the UK
}

Article

Accepted Version

Srinivasan, C.S. (2013) Can adherence to dietary guidelines address excess caloric intake? An empirical assessment for the UK. Economics and Human Biology, 11 (4). pp. 574-591. ISSN 1570-677X doi:

https://doi.org/10.1016/j.ehb.2013.04.003 Available at https://centaur.reading.ac.uk/32415/

It is advisable to refer to the publisher's version if you intend to cite from the work. See Guidance on citing.

To link to this article DOI: http://dx.doi.org/10.1016/j.ehb.2013.04.003

Publisher: Elsevier

All outputs in CentAUR are protected by Intellectual Property Rights law, including copyright law. Copyright and IPR is retained by the creators or other copyright holders. Terms and conditions for use of this material are defined in the End User Agreement.

www.reading.ac.uk/centaur 
Central Archive at the University of Reading

Reading's research outputs online 
CAN ADHERENCE TO DIETARY GUIDELINES ADDRESS EXCESS CALORIC INTAKE? AN EMPIRICAL ASSESSMENT FOR THE UK

\author{
C.S.Srinivasan* \\ Department of Food Economics and Marketing \\ School of Agriculture, Policy and Development \\ University of Reading, UK
}

* Address of corresponding author:

Department of Food Economics and Marketing

School of Agriculture, Policy and Development

Agriculture Building

University of Reading

Reading RG6 6AR

UK

Email: c.s.srinivasan@reading.ac.uk

Telephone: +44-118-3788966

Fax: +44-118-9756467 


\title{
CAN ADHERENCE TO DIETARY GUIDELINES ADDRESS EXCESS CALORIC INTAKE? AN EMPIRICAL ASSESSMENT FOR THE UK
}

\begin{abstract}
The facilitation of healthier dietary choices by consumers is a key element of government strategies to combat the rising incidence of obesity in developed and developing countries. Public health campaigns to promote healthier eating often target compliance with recommended dietary guidelines for consumption of individual nutrients such as fats and added sugars. This paper examines the association between improved compliance with dietary guidelines for individual nutrients and excess calorie intake, the most proximate determinant of obesity risk. We apply quantile regressions and counterfactual decompositions to cross-sectional data from the National Diet and Nutrition Survey (200001) to assess how excess calorie consumption patterns in the UK are likely to change with improved compliance with dietary guidelines. We find that the effects of compliance vary significantly across different quantiles of calorie consumption. Our results show that compliance with dietary guidelines for individual nutrients, even if successfully achieved, is likely to be associated with only modest shifts in excess calorie consumption patterns. Consequently, public health campaigns that target compliance with dietary guidelines for specific nutrients in isolation are unlikely to have a significant effect on the obesity risk faced by the population.
\end{abstract}

Keywords: Calorie intake, Obesity, Dietary guidelines, Public health campaigns, Impact assessment, UK

J EL classification: I10, D10 


\section{Introduction}

Faced with the rising incidence of obesity in their populations, governments in both developed and developing countries are seeking to promote healthier food choices by consumers through a range of economic, regulatory and information measures. Promoting adherence to recommended dietary guidelines for key nutrients is an important element of the strategy for promoting healthier eating. It provides the rationale for a variety of public health campaigns such as the UK Government's "five a day" ${ }^{1}$ campaign to increase fruit and vegetable consumption and the "Change4life - Eat Well, Move More, Live Longer"2 campaign, the European Commission's "Salt Campaign" 3 to reduce salt intake and the US Department of Agriculture's "MyPlate"4 initiative to promote healthier eating. The desirability of conforming to recommended dietary guidelines for specific nutrients also underpins many initiatives for nutritional labelling and proposed fiscal interventions to combat obesity such as "fat” taxes and "thin" subsidies. In this paper, we develop a framework for examining the association between conformity to dietary guidelines for individual nutrients and excessive energy intake, which is the most proximate determinant of obesity risk (J ebb, 2007). Based on our empirical analysis for the UK, we argue that adherence to dietary guidelines for individual nutrients, even if successfully accomplished through public health campaigns and other measures, is likely to be associated with only

1 The UK's 5 A DAY campaign, introduced in 2002-2003, aims to increase awareness of the health benefits of fruit and vegetable consumption, particularly targeting groups with the lowest intakes. For key messages and targeted action under the programme, see http:// www.nhs.uk/ LiveWell/5ADAY/Pages/5ADAYhome.aspx.

2 Change4Life is the UK's national social marketing campaign started in 2009 that aims to prevent people from becoming overweight by encouraging them to eat better and move more. For current details of the campaign see http:// www.nhs.uk/Change4Life/ Pages/ change-for-life.aspx.

3The European Union adopted a "Common Framework for National Salt Initiatives" in 2008 with the objective of reducing the salt content of food products, also encompassing salt consumed in restaurants and catering (European Commission, 2012). For details of implementation of the salt reduction initiative see http:// ec.europa.eu/health/nutrition physical activity/high level group/nutrition salt en.htm

4 "MyPlate" is a communications initiative based on the 2010 Dietary Guidelines for Americans (US Department of Health and US Department of Health and Human Services, 2010) to help US consumers to make healthier food choices. See http:// www.choosemyplate.gov/ for details of the initiative. 
modest changes in patterns of excessive energy intake, and consequently, with only small shifts in obesity risk in the population ${ }^{5}$.

\section{Obesity and Adherence to Dietary Guidelines in the UK}

The Cabinet Office report Food Matters (J arvis, 2008) identifies the promotion of healthier dietary choices by consumers as a key element in the UK Government's food strategy for the $21^{\text {st }}$ century. This follows from the recognition of the enormous health gains that would accrue to the UK if diets matched nutritional guidelines on fruit and vegetable consumption, saturated fats, added sugars and salt intake. The Cabinet Office report estimates that adherence to nutritional guidelines would reduce the risks related to cancer, heart disease and other illnesses leading to 70,000 fewer people dying prematurely every year. Improved dietary choices are also crucial for meeting the challenge of obesity, with over a quarter of adults and $10 \%$ of children in the UK already classified as "obese". In addition to the social impacts, the economic burden of diet related ill-health is estimated at almost $€ 6$ billion a year by way of additional National Health Service costs alone.

The changing Body Mass Index (BMI) profile of the UK adult population based on data from the Diet and Nutritional Survey of British Adults 1986-87 (OPCS, 1991) and the National Diet and Nutrition Surveys of 2000-01(ONS, 2005) and 2008-09 (Bates, Lennox and Swan, 2010) is presented in Table-1 which summarises the quantiles of the BMI distribution in the three time periods. While the average BMI has steadily increased, what is significant and of greater concern is the rightward shift of the BMI distribution. The proportion of adult individuals who are overweight ( $\mathrm{BMI} \geq 25$ and $<30$ ) or obese $(\mathrm{BMI} \geq 30)$ has increased from $40 \%$ to $62 \%$, while the proportion of individuals who are obese has increased from $10 \%$ to $27 \%$.

\section{[Table-1here]}

\footnotetext{
${ }^{5}$ It is important to note that we do not measure adherence to Dietary Reference Values (DRVs) for caloric intake in this paper.
} 
Obesity is a characteristic with a complex set of socio-economic, demographic, environmental and cultural determinants (Ulijaszek, 2007). A wide array of these factors has been examined in the literature, including access to food, lifestyle factors, fast-food consumption (Chou et al., 2004), economic well-being and security (Smith et al., 2009), food advertising (Andryeva et al., 2011), physical activity and the built environment (Salois, 2012, Sandy et al., 2012). The influence of these factors arises through their effect on the two most proximate determinants of body weight - food choice and the resultant nutrient and energy composition of diets and energy expenditure. In this paper, while recognising the wide array of determinants that influence obesity, we focus on the association between the nutrient composition of diets and excessive energy intake and the consequent risk of obesity.

The rising trend in the incidence of obesity has been associated with significant deviations from the recommended dietary guidelines suggested by the World Health Organization (2003) and national public health authorities. These dietary guidelines are chiefly related to the share of energy derived from macronutrients (fats and sub-components, sugars and protein) and the absolute intake levels of fruits and vegetables, fibre, salt and cholesterol. In the US, which reports the highest incidence of obesity in the developed world (OECD, 2012), Volpe and Okrent (2012) report that consumer diets are a long distance away from conformity with the Dietary Guidelines for Americans (US Department of Health and Human Services and the US Department of Agriculture, 2005). Using the Healthy Eating Index (HEI) (US Department of Agriculture, 2010), an overall measure of diet quality based on adherence to the Dietary Guidelines, Volpe and Okrent (2012) find that the average HEI score for food-at-home purchases of US consumers was 56.4, far below the maximum score of 100, which would indicate perfect adherence to the 2005 Dietary Guidelines. Similarly, Guenther et al. (2008) found a low average HEI score of 58.2 based on consumption data from the respondents of the National Health and Nutrition Examination Surveys. Dietary guidelines in the UK (Department of Health, 1991) are presented along with the dietary guidelines suggested by the World Health Organization (2003) in Table-2. Information on trends in adherence to key dietary guidelines in the UK over last the two decades is 
summarised in Table-3. For 2008-09, the average contribution to energy intake from all fats (34.8\%), saturated fats (13.2\%) and non-milk extrinsic sugars (13.5\%) was clearly in excess of the prescribed guidelines, while the contribution of polyunsaturated fatty acids (PUFA) to energy (5.2\%) and average cholesterol consumption were within the acceptable range. Average fruit and vegetable consumption fell well short of the recommended intake (400 grams per day), as did the intake of dietary fibre. The average consumption of salt remained considerably higher than the recommended guideline (less than 2.36 grams of sodium per day). The average figures, however, mask the true extent and severity of non-compliance with the recommended guidelines. From an obesity risk perspective, it is the large proportion of non-compliers in the population whose dietary choices are a matter of concern. For instance, the average intake of energy from saturated fats (13.5\%) may not appear to bea large violation of the recommended guideline for saturated fats. However, Table-3 shows that $86.6 \%$ of the adult population consume saturated fats in excess of the recommended amount, with $25 \%$ obtaining more than $15 \%$ of energy from saturated fats.

\section{[Table-2 here]}

\section{[Table-3 here]}

The dietary guidelines suggested by the Department of Health (DoH) and the World Health Organization (WHO) are based on an extensive review of medical and nutrition literature examining the relationship between dietary choices/ nutrient intakes and the prevalence of chronic disease and ill-health. They are intended to reduce the incidence of a range of chronic diseases such as diabetes mellitus, cardiovascular disease, hypertension, stroke, certain types of cancer and also combat obesity. It is no doubt true that not all of the dietary guidelines are aimed at combating obesity. However, the promotion of diets derived from these guidelines (such as the US Department of Agriculture's "MyPlate" and the UK Food Standard Agency's "Eatwell Plate") is a crucial element of the strategy to improve the dietary patterns of the population. The reduction in the risk of obesity that can be achieved through adherence to the recommended dietary guidelines remains an empirical question. It is this 
question, which could be of considerable interest to those designing public health campaigns and other measures to promote healthy eating, that we address in this paper. We develop a framework to assess the potential changes in the distribution of excessive energy intake in the population if adherence to prescribed dietary guidelines for nutrient intakes is successfully achieved.

We note that dietary guidelines in the UK also include Dietary Reference Values (DRVs) for overall energy intake. The Scientific Advisory Committee on Nutrition (2011) provides DRVs based on estimated average requirements (EARs) of infants, children, adolescents and adults. Clearly, adherence to recommended energy intake guidelines would have a significant effect on the obesity risk of the population. However, our framework considers only the potential effects associated with adherence to dietary guidelines for individual nutrients/ foods. This is because public health campaigns and other measures to promote healthier diets focus predominantly on adherence to individual nutrient intake guidelines and influence calorie consumption only indirectly. Our interest is in the patterns of calorie intake that are likely to emerge as a consequence of compliance with nutrient intake guidelines.

In assessing the potential effects of adherence to dietary guidelines on obesity, it is tempting to model BMI (or other obesity indicators) as a function of intakes of nutrients or adherence to guidelines. However, using such an approach with cross-sectional data sets (which comprise the majority of nutrition data sets) raises a number of problems and issues which have been well recognised in the literature. J ebb (2007) notes that "cross-sectional studies are confounded by post-hoc effects in which dietary differences between individuals arise as a consequence of obesity rather than as a causal factor" (p. 93). Variyam et al. (2002) observe that nutrition studies using self-reported data intakes fail to find a strong positive association with between energy intake and obesity. This is attributed to the under-reporting of intakes by overweight persons and also to the possibility that at any point in time, a proportion of overweight persons may be on weight-loss diets. Rosenheck (2008) finds 
"discrepant associations between frequent fast food consumption, increased energy or overweight in terms of BMI" (p. 535), with a number of studies finding a negative correlation between BMI and fast food consumption. Data in cross-sectional surveys do not contain all the information for analysing the determinants of BMI, as BMI observed at any point in time is the result of a lifetime of consumption and habits (Komlos and Brabec, 2011). Therefore, relating BMI directly to dietary intakes in a cross-sectional setting may not be a useful approach for assessing the obesity implications of adherence to dietary guidelines ${ }^{6}$. In a cross-sectional setting, observed dietary intakes can signal only the potential risk of weight gain/ obesity faced by different segments of the population.

A second issue to be addressed is that the effect of adherence to dietary guidelines may vary along the distribution of obesity risk. For instance, the effect of a unit increase in the share of energy derived from saturated fats may be very different for individuals facing different levels of obesity risk. A number of studies in the literature have used multiple linear or logistic regressions to analyse the effects of dietary intakes on BMI. These approaches assess the mean response of the outcome variable to changes in explanatory variables. In these approaches, the effect of the covariates is same along the whole range of outcomes - for instance, the effect of a unit increase in fat consumption on BMI would be the same for an underweight or obese individual. In designing public health campaigns, we are more interested in the effect of adherence to guidelines in the upper tails of the outcome variable (denoting higher obesity risk). The heterogeneity of response to adherence to different dietary guidelines at different levels of overweight/ obesity risk is a key element of interest. We would like to explore the hypothesis that the effects of adherence to dietary guidelines could vary along the whole distribution of obesity risk and could be significantly different from the mean response values in the upper tail of the obesity risk distribution. The effects of compliance could be very different for potentially obese and non-obese individuals.

\footnotetext{
${ }^{6}$ The confounding "post-hoc" effects are also evident in the NDNS data set used in this paper. A regression of BMI on nutrient intakes yields a negative coefficient for the share of fat in energy intake - giving the misleading implication that an increase in the share of fat in energy intake will lower BMI.
} 
A third issue is that in assessing the potential effects of adherence to dietary guidelines, we are more interested in how the population distribution of obesity risk would change as a result of compliance, rather than in the average effects of compliance with dietary guidelines. Even if the entire population were to conform to the recommended dietary guidelines, there would still be substantial variation across individuals in the degree of conformity. We are interested in the potential distribution of obesity risk that can be expected in a population of compliers.

\section{Methods}

Given the poor correlation between BMI and dietary intakes in a cross-sectional context, we develop a proxy indicator for obesity risk relying on one of the few facts about obesity that is not controversial - "that weight is only gained when energy intake exceeds energy needs over a prolonged period"(J ebb,2007, p.98). Large scale nutrition data sets, however, do not record food consumption over an extended period and we have to rely on indicators derived from cross sectional data. We build a measure of "excess calorie consumption" (ECC) and model it as a function of the nutrient composition of diet. ECC is computed as (Total calories consumed/Total calorie need)*100. If total calories consumed equal total calorie need, then ECC equals 100. ECC <100 denotes deficient calorie consumption. Adherence to dietary guidelines influences obesity risk via its association with ECC. We use ECC in our analysis because it clearly signals obesity risk and at the same time appears to have a systematic association with the nutrient composition of diets available from cross-sectional data. To assess calorie need, we rely on the predictive equations for resting energy expenditure proposed in the literature (Frankenfield et al., 2005, Hofesteenge et al., 2010). These predictive equations are all based on empirical studies that relate an individual's resting energy requirement to age, gender and anthropometric characteristics. In this paper we have based our measure of ECC on the Harris-Benedict (HB) equation7. The BMR derived from

\footnotetext{
${ }^{7}$ The Harris-Benedict equation estimates the Basic Metabolic Requirement (BMR) as: $\mathrm{BMR}_{\text {MALE }}=66+13.7 \mathrm{xweight}(\mathrm{kgs})+5 \mathrm{xheight}(\mathrm{cms})-6.8$ xage (years) $\mathrm{BMR}_{\mathrm{FEMALE}}=655+9.6 \mathrm{xw}$ eight $(\mathrm{kgs})+1.8 \mathrm{xheight}(\mathrm{cms})-4.7 \mathrm{x}$ age $($ years $)$
} 
the HB equation is multiplied by a factor reflecting a person's level of physical activity to arrive at the total calorie requirement ${ }^{8}$. The estimation of calorie requirement for individuals as a multiple of BMR based on an index of physical activity has been used by the World Health Organization (2001) in assessing human energy requirements, the Scientific Advisory Committee on Nutrition (2011) in the UK for deriving the dietary reference values for energy for different segments of the population and in other studies on energy requirement in humans (e.g., Pellet, 1990).

The ECC measure derived from observation of food consumption over a short period of time in cross-sectional data may not reflect the cumulative consumption patterns of the respondents. Some individuals may be on weight loss diets and their observed nutrient intake profile may not reflect their consumption history ${ }^{9}$. The observed pattern of ECC will translate into the risk of obesity only if it is maintained over a period of time. However, the NDNS is a nationally representative sample, and the ECC distribution derived from it will reliably reflect the more stable consumption patterns for the population as a whole. Our approach to assessing the effects of conformity to dietary guidelines requires only a robust approximation of the ECC distribution of the population, which the NDNS can provide.

With a measure of ECC derived from the HB equation, we use a quantile regression (QR) (Koenker, 2005) approach to explore how dietary composition and nutrient intakes (linked to the dietary guidelines), physical activity and a set of health related lifestyle choices (smoking and alcohol consumption) influence ECC. The QR method allows the effect of the

\footnotetext{
The Harris-Benedict equation is, perhaps, the oldest of such predictive equations and is believed to overestimate energy requirements in the context of current day lifestyles. However, the measure of excess calorie consumption based on it gives a better fit when regressed on nutrient composition of diet compared to some other equations (such as the Miffin-St.J eor equation).

8 The BMR derived from the HB equation is generally multiplied by a factor ranging from 1.2 to 1.9 depending on a person's level of physical activity to arrive at the total calorie requirement. The National Diet and Nutrition Survey data set used in this paper records average physical activity scores that range from 33 to 100 , with those having a score above 40 considered to have a relatively active lifestyle. The multiplicative factors used to derive the total calorie requirement were based on these scores.

${ }^{9}$ For such individuals, the observed pattern of nutrient intakes, if maintained, will influence the future likelihood of weight gain/ obesity.
} 
explanatory variables to vary along the whole range of the outcome variable - ECC in this case. The method allows us to understand how the association between adherence to dietary guidelines and ECC varies across groups at different levels of ECC. The relevance of QR in diet and nutrition analysis arises from the interest in the tails of the dietary outcome distribution - characterised by inadequate/ excessive energy intake. A key point of interest in our analysis is the effect of conformity to dietary guidelines on groups at the highest risk of obesity. An increasing number of applications of QR are emerging in diet and nutrition analysis (Variyam et al., 2002; Sinha, 2006). A recent application examined the impact of socio-economic determinants on fruit and vegetable intakes in the UK (Boukouvalas et al., 2009).

The QR results are used to carry out a "counterfactual decomposition" to assess the shifts in the distribution of excess calorie intake associated with adherence to dietary guidelines. We use the technique used by Machado and Mata (2005) which allows changes in the distribution of the outcome variable to be decomposed into "co-efficient" and "covariate" effects. For instance, if ECC is related to fat consumption, then a change in ECC over two time periods could be due to an increase (or decrease) in fat consumption (covariate effect) and/ or due to a change in the effect of fat consumption on ECC (co-efficient effect). The same technique can also be used to assess how the distribution of the outcome variable would change if the distribution of one the covariates were to change, other covariates remaining the same. We use this counterfactual decomposition technique to assess how the distribution of ECC would change if the entire population were to conform to individual dietary guidelines or combinations thereof. The dietary adjustment process modelled here involves the non-compliant segments of the population adopting the diets of the compliant segments of the population. The changes in ECC are those associated with consumers shifting to diets compliant with dietary guidelines. 


\section{Data and Variables}

This paper uses data from the UK's National Diet and Nutrition Survey (NDNS) for 2000-01 which collected diet and nutrition information from a nationally representative sample of 2251 adults $^{10}$ aged 19-64. The survey collected detailed information on foods consumed (at home and outside the home) based on food diaries maintained by respondents. The survey also collected social and demographic information at the household level and data on anthropometry, health parameters and physical activities of the respondents. The data set provides nutrient conversion factors for each food item covering a total of 51 macro and micro nutrients. A number of "derived variables"11 are also provided such as the total energy intake, share of different macronutrients in energy intake, consumption of fruits and vegetables, salt, fibre, cholesterol and other nutrients which are related to the recommended dietary guidelines. After omitting respondents with incomplete responses/ data and further omitting respondents who reported that their eating had been affected by ill-health, there were observations on 1344 individuals.

\section{[Table-4 here]}

The variables used in this paper are summarised in Table-4. The measure of ECC is derived by subtracting the calorie requirement as estimated from the HB equation (and adjusted for physical activity scores) from the total calories consumed. The dietary composition/intake variables included are those related to the DoH's prescribed dietary guidelines and include the share of energy from macronutrients and intakes of fruits and vegetables, fibre, salt and cholesterol. Cigarette smoking and alcohol consumption were included as "lifestyle" factors affecting excess calorie intake. In addition to the average physical activity score for each individual, the occupational category (manual or non-manual) was included as a factor

\footnotetext{
${ }^{10}$ Pregnant and breast feeding women were excluded from the NDNS-2000-01.

${ }^{11}$ The NDNS-2000-01 food diaries record the details of different types of foods and their quantities consumed by the respondents over a 7 day period. The derived variables are computed using the standard nutrient composition of different foods and aggregating across different foods consumed by respondents. For instance, the share of energy derived from fats is computed by aggregating the fat content of different foods and working out the total energy derived from fats. Similarly, the consumption of other nutrients (e.g., salt, cholesterol, fibre) is derived by aggregating the content of those nutrients in the different food items consumed by the respondents.
} 
influencing energy expenditure. Age, gender and race/ ethnicity ${ }^{12}$ were the demographic variables included in the model. Race/ ethnicity was included to assess whether the effect of adherence to dietary guidelines varies across these groups (possibly as a result of genetic differences).

It is well-recognised in the literature that large-scale nutrition surveys such as the NDNS are subject to significant under-reporting of nutrient/ food intakes. The extent of underreporting may vary with respondent characteristics (e.g., BMI) and could be different for different nutrients. Rennie et al. (2007) estimate that the extent of under-reporting of energy intake in the NDNS could be as high as $25 \%$, with under-reporting being higher in obese men and women. At the same time, over-reporting of physical activity in large-scale surveys has also been noted in the literature (Rzewnicki et al, 2003). This may arise from differing social or cultural perceptions about what constitutes physical activity or from respondents' desire to give replies that are seen as being socially appropriate (Warnecke et al, 1997). The underreporting of nutrient intakes and over-reporting of physical activity may imply that ECC may not be estimated precisely and may be subject to a significant downward bias. This is an important caveat to be kept in mind when interpreting the data on ECC. The counterfactual decomposition method used in this paper assesses the likely change in the ECC distribution associated with adherence to dietary guidelines (relative to existing patterns). The results provide useful insights into the direction and magnitude of changes in ECC that can be expected from improved conformity to dietary guidelines, notwithstanding the potential downward bias in ECC estimated from NDNS data.

\section{Results and Discussion}

\subsection{Quantile Regression Results}

The linear QR model was estimated was:

12 The ethnicity variable in the NDNS 2000-01 refers to self-reported membership of one of the following groups - White, Black-Caribbean, Black-African, Black-Other, Indian, Pakistani, Bangladeshi, Chinese or 'None of These'. These groupings include an element of the region/ country of origin besides race. Therefore, we use the term "race/ ethnicity" to describe these groups - but have grouped these nine categories in to four - White (reference group), Asian, Black and Others. 
$\mathrm{ECC}_{\tau}=\alpha_{1 \tau}+\beta_{1 \tau}$ satfat $+\beta_{2 \tau}$ pufat $+\beta_{3 \tau}$ monofat $+\beta_{4 \tau}$ sugar $+\beta_{5 \tau}$ prot $+\beta_{6 \tau}$ star $+\beta_{7 \tau}$ frveg + $\beta_{8 \tau}$ fibre $+\beta_{9 \tau}$ sodium $+\beta_{10 \tau}$ smoking $+\beta_{11 \tau}$ alcoh $+\beta_{12 \tau}$ chol $+\beta_{13 \tau}$ phyact $+\beta_{14 \tau}$ age + $\beta_{15 \tau}$ female $+\beta_{16 \tau}$ race ethnic $+\beta_{17 \tau}$ manual $+\varepsilon_{\tau}$

where the dependent variable ECC denotes excess calorie consumption, the explanatory variables are as described in Table-4, $\tau$ denotes quantiles and $\varepsilon$ is the error term. All the continuous explanatory variables were centred at the median for convenience of interpretation. Conditional quantiles were estimated for the dependent variable at 90 different quantiles from $5^{\text {th }}$ to $95^{\text {th }}-$ and the results for five quantiles - the $5^{\text {th }}, 25^{\text {th }}, 50^{\text {th }}$ (median), 75th and 90th - are presented. The estimation was done using the 'quantreg' module in the R statistical software package. Standard errors and confidence intervals were computed using the bootstrap procedure described in Koenker (2005) which is incorporated in the "quantreg" module.

In the QR model above, the coefficients for the explanatory variables in any quantile give us the effect of a unit change in the explanatory variable with all other continuous variables held at the sample median and categorical variables held to the base category. Our model incorporates two different types of dietary guidelines. The guidelines in the first set are related to macronutrients and are expressed as shares of food energy intake. An increase in the share of food energy for one macronutrient (e.g., saturated fats) implies a decrease in the share of some other macronutrient ${ }^{13}$. The coefficient of the share of a macronutrient in energy intake in the above model can be interpreted as the net effect on ECC of moving to a diet with a unit (percentage point) increase in the energy share of that macronutrient. It is important to note that the regression coefficients in the QR model are not to be interpreted as the physiological effects of a unit change in the share of energy derived from a macronutrient ${ }^{14}$. The second set of guidelines is expressed in terms of the absolute level of

\footnotetext{
${ }^{13}$ It may be noted that the share of energy from all macronutrients will sum to $100 \%$. A unit increase in the share of energy from one macronutrient implies a decline in the share of some other macronutrient. In the equation above, the share of energy derived from carbohydrates (other than from sugar and starch) has been omitted as it is treated as "residual".

${ }^{14}$ The physiological effects of changes in the macronutrient composition of diet on calorie intake may operate through energy density effects and through the differing effects of macronutrients on appetite
} 
intake - for fruits and vegetables, fibre, sodium (salt) and cholesterol consumption. The coefficient for fruit and vegetable intake can be interpreted as the effect of moving to a diet with a unit increase in fruit and vegetable intake. The consumption of fibre, salt and cholesterol can generally increase only as a result of increased consumption of foods in which they are constituents. The effect of increased consumption of these nutrients on calorie consumption arises on account of the increase in consumption of the associated foods ${ }^{15}$. We would, therefore, expect the coefficients of these nutrients to be positive unless there are large offsetting effects. For instance, increased consumption of foods containing fibre would add to calorie consumption- so we would expect the coefficient of fibre to be positive. A negative coefficient would arise only if the move to a diet with a higher level of fibre consumption is associated with a reduction in calorie intake from other foods in the observed diets of the population. The effects of smoking and alcohol consumption may arise from their effects on behavioural, sensory and physiological processes influencing the ingestion of calories from all other foods. Alcohol, however, is itself a source of calories, therefore, its coefficient will reflect the net effect of a unit increase in alcohol consumption arising from its own calorie content and its effect on consumption of other foods. As noted previously, the WHO and UK dietary guidelines are based on an extensive survey of the literature on how individual nutrient intakes affect obesity and chronic diseases. We do not examine the physiological effects of changes in individual nutrient intakes here. Our main interest in this paper is to assess (1) how the changes in ECC associated with conformity to dietary guidelines vary across ECC quantiles, i.e., across segments of the population with low or high risk of obesity and (2) how these effects are likely to play out empirically in a population of compliers (in the context of an ecological study of free living populations).

control and satiety (Stubbs et al., 2000). The effect on calorie intake modelled here arises as result of moving from a diet with a lower share of energy from a macronutrient to a diet with a higher share of energy from that macronutrient.

15 The increased consumption of foods containing fibre, salt or cholesterol may be in addition to food already being consumed or it may substitute (fully or partially) for other foods. The coefficients of these nutrients in the model can be interpreted as the effect of increased consumption of these nutrients, the composition of the diet in terms of all other nutrients remaining the same. 
Table-5 presents the results for QR estimates. The ordinary least squares (OLS) estimates are also presented in the first column of the table to facilitate comparisons. The table presents the coefficients and $p$-values for all the explanatory variables for the selected set of quantiles from the $5^{\text {th }}$ to the $90^{\text {th }}$. Figures $1 \mathrm{~A}$ and $1 \mathrm{~B}$ present the graphs for each explanatory variable showing the coefficients estimated at each of the selected quantiles. The shaded areas in the graphs show the 95\% confidence intervals associated with the co-efficient estimates. The OLS estimates and the associated 95\% confidence intervals, shown as the red line and dotted lines respectively, are superimposed on the quantile regression graphs. Each graph shows how the co-efficient of the explanatory variable changes as we move from the lower quantiles to the higher quantiles of the outcome variable (ECC) with all other continuous variables held at their median values and categorical variables held to the base category. For instance, the graph for the intercept term shows how ECC varies across quantiles for white males who are non-manual workers, when age, nutrient consumption, lifestyle factors and physical activity are at their median values.

\section{[Table-5 here]}

\section{[Figures-1A and $1 B$ here]}

The graphs in Figure-1 highlight the differences between the QR coefficients and OLS coefficients at different quantiles. These differences are marked in the upper quantiles which represent high levels of ECC. The divergence of the QR estimates from the OLS estimates in the top quantiles of ECC suggests that the OLS estimates may provide a somewhat misleading representation of the association between the nutrient composition of diets and ECC for the segment of the population that faces the highest risk of obesity. The QR results discussed below show how the association between the nutrient composition of diets (and other explanatory variables) and ECC varies across the quantiles of ECC.

An increase in the share of energy derived from saturated fats is associated with increased ECC. The OLS results suggest that a one percentage point increase in energy share from 
saturated fats is associated with a 0.67 percentage point increase in ECC. But this effect is not significant in the top quantiles of ECC. The coefficient of the share of food energy from PUFA varies in sign across quantiles but is not significant in any of them. The coefficient of the share of food energy from monounsaturated fats is negative in all quantiles suggesting that an increased share is associated with a reduction in ECC, but the effect is significant only in the lower quantiles. Increased cholesterol consumption is associated with higher levels of ECC in all quantiles (in interpreting the cholesterol coefficient, note that units for cholesterol are milligrams). Increased intake of dietary fats has been found to be an important determinant of obesity in several studies (Lissner and Heitman, 1995; Golay and Bobioni, 1997, Hill and Peters, 1998; Bray and Popkin, 1998; Hill et al., 2000; Astrup, 2001). At the same time, other studies (Willett, 1998a; 1998b; 2002) have reported that reduction in dietary fat intake in obese individuals is not associated with significant weight loss. Our results suggest that the findings from different studies need not be viewed as being contradictory. While the mean response to an increase in the share of saturated fat in energy intake is an increase in excess calorie consumption (as shown by the OLS results in Table-5), our results show that in the top quantiles of ECC (i.e., for persons at the highest risk of obesity) a reduction in the share of energy from saturated fat may not be associated with significant changes in ECC.

An increase in the share of food energy derived from non-milk extrinsic sugars (NMES) is associated with increased ECC. The magnitude of the effect increases as we move up the quantiles and is highly significant in the upper quantiles. The results suggest that reducing the share of energy derived from NMES (e.g., by avoiding fizzy drinks) does have a significant association with reduced ECC. The share of energy from NMES appears to have a stronger effect on ECC than the share of energy derived from fats. These results appear to confirm the strong link between the consumption of added sugars and obesity observed in a number of studies (Bolton-Smith and Woodward, 1994; Pereira, 2006) particularly in the context of childhood obesity (Ludwig et al., 2001; Gillis and Bar-Or, 2003, Apovian, 2004, Berkey et al., 2004). 
An increase in the share of energy derived from proteins has a large negative association with ECC - which is significant in all quantiles. OLS results suggest that a one percentage point increase in the food energy share from proteins is associated with a 2.2 percentage point decline in excess calorie intake. The magnitude of the effects of the share of protein in calorie intake is again much larger than that of the share of saturated fats. The inverse association between protein intake and obesity/ weight gain appears to be well-established (WesterterpPlantenga et al., 2004, Merchant et al., 2005, Astrup, 2005; Leidy et al., 2007). Our results show that a shift to diets with a sharp increase in the share of energy from proteins is associated with a reduction in ECC. This ECC reducing effect may explain some of the weight loss claims of protein rich diets.

The coefficient of fruit and vegetable consumption suggests that increased consumption is associated with a small increase in ECC, but the effect is generally not significant in most of the quantiles. The small positive association of fruit and vegetable consumption with ECC appears to be largely consistent with the results of intervention studies (e.g., Whybrow et al., 2006) that supplementary fruit and vegetable intake has no significant effect on energy intake. Epidemiological studies (Tohill et al., 2004) also generally show only a weak negative association between fruit and vegetable consumption and BMI.

The coefficients of salt and fibre are expectedly positive and significant in all quantiles and increase as we move to the higher quantiles. Several intervention studies based on shortterm supplementation of fibre intake (through fibre isolates or fibre-supplemented foods) have found a negative effect of increased fibre consumption on energy intake (BurtonFreeman, 2000). It must, however, be noted that the coefficient of fibre in our model reflects the effect of increased consumption of fibre-containing foods (that are present in the NDNS basket) while leaving the overall nutrient composition of diets unchanged. There is no evidence in the estimates of large "offsetting" effects arising from salt or fibre consumption. Cigarette smoking does not appear to have a significant assoication with ECC in any of the 
quantiles ${ }^{16}$. However, increased alcohol consumption is clearly associated with reduced ECCan effect which is consistent and significant across all quantiles and is more pronounced in the higher quantiles of ECC. This suggests that the increase in calories from a unit of alcohol is more than offset by reduced intake of calories from other foods ${ }^{17}$.

ECC increases with the age of the respondents. This effect is small but significant across quantiles and increases as we move up the ECC quantiles. The gender of the respondent has a much larger effect on ECC. The OLS results suggest that ECC of females is lower by 4.83 percentage points in relation to that of males. The effect of gender declines (from 7.21 percentage points in the $5^{\text {th }}$ quantile) as we move to the higher quantiles but is still substantial (3.36 percentage points) and significant in the $90^{\text {th }}$ quantile. Asian race/ ethnicity is associated with substantially higher ECC (2.89 to 12.34 percentage points higher) compared to Whites (the base group). This effect is much more pronounced in the lower quantiles than in the higher quantiles of ECC. A similar association is seen in the case of the Black racial/ ethnic group although the effects are smaller and not significant in many of the quantiles.

As expected, increased levels of physical activity are associated with reduced ECC. The effect of physical activity is largest in the top quantiles of ECC. Thus, individuals who are most prone to obesity through excess calorie intake will benefit the most from increased physical

\footnotetext{
${ }^{16}$ Although a number of studies have found an inverse relationship between smoking behaviour and body weight and a rebound weight gain on cessation of smoking, the empirical evidence on the effect of smoking on body weight is mixed. Smoking may affect body weight not only through its effect on appetite and energy intake, but also through its effect on metabolism (Wack and Rodin, 1982), fat accumulation and physical activity. Using genetic instruments to model the effects of smoking, Wehby et al (2012) find considerable heterogeneity of effects across BMI quantiles - with smoking increasing BMI at low/ moderate levels of BMI but decreasing BMI at high levels of BMI. The coefficient of smoking in our model gives us only the effect on ECC.

${ }^{17}$ Excessive alcohol consumption has been found to be associated with reduced intake of energy from fats and carbohydrates (Windham and Hansen, 1983). However, excessive alcohol consumption causes liver and health disorders and reduced energy intake may be attributable to the effects of the health condition rather than to a diminution of appetite caused by alcohol. Moderate alcohol consumption has been found to provide short term stimulation of energy intake in a number of studies (Poppitt et al, 1996; Yeomans, 2004). However, this short term stimulation of energy intakes can be offset by lower energy intakes in later meals or on alcohol free days. NDNS data provide the average consumption over a 7 day period based on respondent diaries. An overall negative effect of alcohol consumption on ECC can be consistent with the short term stimulation of energy intake provided by moderate alcohol consumption.
} 
activity. However, it should be noted that the effect of physical activity is much smaller compared to the effects of age, gender and race/ ethnicity. The occupational category (manual or non-manual) has an interesting association with ECC. In the lower quantiles, a manual occupation is associated with reduced ECC. But in the higher quantiles a manual occupation is associated with sharp increases in excess calorie intake in relation to those in non-manual occupations.

The QR results are useful in identifying segments of the population that are likely to be prone to excessive energy intakes (and hence at the risk of obesity). Public health campaigns to promote healthier eating could target or prioritise these groups. For instance, our results suggest that older males in manual occupations are prone to excessive calorie consumption. Similarly, the large and significant QR coefficients associated with Asian race/ ethnicity (across ECC quantiles) suggest that this group is prone to excessive calorie consumption and hence may need to be prioritised even if their average calorie consumption patterns are not very different from those of the reference (White) group ${ }^{18}$.

\subsection{Counterfactual Decompositions}

The QR results presented in the previous section give us the conditional quantile effects of changes in nutrient consumption patterns on ECC. The coefficient of any variable (e.g., share of saturated fats in food energy) at different quantiles gives us the effect of a unit change in the variable on the outcome variable (ECC) at the relevant quantile of the outcome variable, holding all other covariates constant at their median level. The QR coefficients do not convey the "unconditional" quantile effects, i.e., the effect of a unit change in the variable when the covariates are distributed as in the sample or when their distribution changes in a particular way (e.g., when the entire population adheres to a particular dietary guideline). It is this "unconditional" quantile effect that we are interested in while assessing the effect of measures to promote healthy eating. In this section we present the results from a counterfactual decomposition exercise using the method suggested by Machado and Mata

${ }^{18}$ From a prevention perspective, it may always be appropriate to target the younger age group before obesity sets in. These results only provide insight into the groups likely to be prone to excessive calorie intake based on their current consumption patterns. 
(2005) to examine the changes in the distribution of ECC if (1) individual dietary guidelines are adhered to and (2) combinations of dietary guidelines are adhered to. The counterfactual decomposition exercise does not convey the effect of every individual in the population complying with the recommended dietary guidelines by switching to a specific modified diet (which is the kind of insight gained from intervention studies or randomised control trials). Instead, it tells us what the distribution of ECC (and hence the risk of obesity) in the population would be if the consumption pattern of the entire population were to be similar to that of a sub-population of compliers.

\section{[Table-6 here]}

Table- 6 summarises the results of the counterfactual decomposition exercise. It shows the mean and selected quantiles of the distribution of ECC that would prevail under adherence to individual dietary guidelines or combinations thereof. The last column shows the percentage of adults not consuming excess calories under each of the scenarios. The first row shows the distribution of ECC for a random sample from the population (based on the QR model and data from the NDNS 2000-01) and provides a benchmark for comparison. Figure-2 shows the shift in the cumulative density function of ECC associated with adherence to individual dietary guidelines compared to the benchmark distribution, whereas Figure-3 shows the shift in the cumulative density function of ECC associated with adherence to combinations of guidelines. The benchmark figures from the NDNS 2000-01 suggest that nearly $38.4 \%$ of the adult population is deficient in calorie consumption relative to need. This appears to be inconsistent with the worsening obesity profile of the population. However, in interpreting the figures, we need to take into account the under-reporting of energy intakes in dietary surveys, as discussed earlier. In assessing the association of adherence to dietary guidelines with ECC, it may, therefore, be useful to focus on the percentage point change in ECC rather than on the implied level of calorie consumption which may be subject to considerable under-reporting.

\section{[Figure-2 here]}




\section{[Figure-3 here]}

Table- 6 shows that in the case of macronutrients, adherence to individual guidelines is associated with a downward shift in ECC at all the selected quantiles, except in the case of proteins and poly-unsaturated fatty acids (PUFAs) where it has the opposite effect. In the case of proteins we have seen that the QR coefficients of the share of food energy from proteins are all negative. Adherence to the protein guideline involves a reduction in the average share of proteins in food energy and, therefore, shifts ECC upward at the selected quantiles. Among individual nutrient guidelines, it is adherence to the saturated fat guideline that is associated with the largest reductions in ECC. Conformity to this guideline reduces ECC by 6-10.8 percentage points in different quantiles compared to the benchmark and increases the percentage of adults not consuming excess calories to $52.5 \%$ from the benchmark figure of 38.4\%. Adherence to the NMES guideline is also associated with large changes in ECC, reducing ECC by 4.9 - 8.2 percentage points and increasing the percentage of the conforming adult population to over $50 \%$. Conformity to the guideline for food energy from all fats ( $<33 \%)$ is associated with more modest reductions in ECC of 4.6-6.1 percentage points in different quantiles. For all fats, saturated fats and NMES, the ECC reducing effect of compliance is attenuated in the top quantile, i.e., the ECC reduction in the $90^{\text {th }}$ quantile is less than that in the $75^{\text {th }}$ or median quantile. This is consistent with the conditional QR results and suggests that ECC reducing effects of compliance may be smaller for those at the highest risk of obesity.

Adherence to the guidelines for fruit and vegetable, fibre, sodium and cholesterol intake is associated with increased ECC, with the magnitude of the effect increasing as we move up the ECC quantiles. The shifts in ECC associated with adherence to these guidelines need to be interpreted somewhat differently. As already noted, these guidelines are specified in terms of absolute levels of intake rather than in terms of their contribution to food energy. Table- 6 shows that adherence to the fibre guideline would be associated with increased ECC and would substantially increase the share of the population consuming excess calories. As 
may be seen from Table-3, average fibre consumption in UK adults is much lower than the recommended guideline with $84.3 \%$ of the population not conforming to the guideline in 2000-01. Adherence to the guideline will call for substantial increases in fibre consumption and consequently for increased consumption of fibre containing foods. The QR model is anchored in the consumption patterns of the respondents in the NDNS 2000-01. The effect of adherence to the fibre consumption guideline in Table-6 is the effect of achieving conformity to this guideline in isolation, through adoption of consumption patterns of those who met the guideline in NDNS 2000-01. The increase in ECC associated with adherence to the fibre guideline may be much less if adherence were to be brought about through consumption of fibre-rich foods different from those in the consumption basket of NDNS 2000-01. The main insight here is that in promoting adherence to guidelines (specified in terms of levels of intake) the choice of foods through which adherence is brought about is very important. Increased fibre consumption may have health benefits, but achieving conformity to the fibre guideline may also have the undesirable consequence of increasing ECC. A similar point may be made about adherence to the fruit and vegetable guideline. Achieving adherence to the guideline in isolation by "imitating” the consumption patterns of compliant individuals may have the effect of increasing ECC. In the case of sodium (salt) and cholesterol, adherence to the guidelines requires a reduction in consumption through reduced consumption of associated foods. Conformity to guidelines related to salt and cholesterol would be associated with substantially reduced levels of ECC and may well have a large effect on obesity risk. The above results show that conformity with individual dietary guidelines in isolation may be associated with very different effects on ECC and may have unintended adverse effects on ECC in certain cases.

The second half of Table- 6 shows the changes in ECC associated with adherence to different combinations of dietary guidelines - the combinations shown are those associated with the largest shifts in ECC. Combined adherence to the saturated fats and NMES guidelines is associated with larger reductions in ECC (mean of 16.7 percentage points) than adherence to individual guidelines. Interestingly, the effect of joint adherence to the saturated fats and 
NMES guidelines is attenuated (and even changes sign in the $95^{\text {th }}$ quantile) when it is combined with the fruit and vegetable guideline. Compliance with the saturated fats and NMES guidelines in combination with the fibre guideline is associated with an increase in ECC in all the quantiles. However, the ECC reducing effects of simultaneous compliance with the saturated fats and NMES guidelines are considerably enhanced when combined with compliance with the guideline for sodium intake. It is adherence to this combination of guidelines that appears to produce the largest shift in the ECC distribution. There is a 44.6 percentage point decline in ECC in the $95^{\text {th }}$ quantile and 36.3 percentage point decline in the $75^{\text {th }}$ quantile, with the proportion of the population not consuming excess calories increasing to $85.7 \%$ from the benchmark figure of $38.4 \%$. Simultaneous compliance with all the dietary guidelines expectedly produces a large shift in the ECC distribution, although, interestingly, it is marginally smaller than that produced by joint compliance with the saturated fats, NMES and sodium guidelines (on account of the ECC increasing effects of adherence to the fruit and vegetable and fibre intake guidelines). When all dietary guidelines are simultaneously complied with, $85 \%$ of the population does not consume excessive calories.

Our results contrast sharply with those reported in the literature on the impacts of changes in dietary intakes or nutrient composition of diets on obesity (e.g., studies on the extent to which high dietary fat consumption is implicated in obesity $\left.{ }^{19}\right)$. The results reported in the literature are mostly those of intervention studies or randomised control trials where a group of participants modify their diets (e.g., adopt a low fat diet), ceteris paribus, over a period of time. Our results on the effects of adherence to dietary guidelines differ sharply from those reported in these studies because we model the dietary adjustment process differently. In our empirical model, conformity to dietary guidelines is achieved through non-compliers adopting the diets of compliers (observed in the data). The counterfactual decomposition (CFD) exercise examines how the ECC distribution of the population would shift if the entire population were to adopt the diets of the sub-population of compliers. Such an adjustment process is more appropriate for modelling the dietary changes of free living populations in

${ }^{19}$ We have referred to some the studies in the discussion of the QR results (Section 5.1) 
response to public health campaigns rather than the (controlled) dietary changes imposed in intervention studies. The main reason why adherence to dietary guidelines produces such limited shifts in the ECC distribution is because the compliant segments of the population also consume excessive energy. Given the nature of the dietary adjustment process assumed in the paper, it is important that our QR and CFD results are not interpreted as the physiological effects of changes in nutrient composition of diets (e.g., a unit increase in the share of energy derived from fats). The "effects" of compliance with dietary guidelines on ECC that we report from our empirical model arise as a result of non-compliant diets being replaced with compliant diets observed in the population.

\subsection{Implications for Combating Obesity}

We have modelled ECC as a function of nutrient composition of diets, lifestyle factors, physical activity and demographic variables. Persistent excessive energy intake in relation to need unambiguously signals obesity risk. Our results, therefore, provide a number of insights into how compliance with dietary guidelines is likely to influence the distribution of obesity risk in the population. Effects of adherence to individual dietary guidelines vary considerably and the potential reduction in obesity risk (or "returns") from adherence to specific guidelines can vary across ECC quantiles (i.e., across groups with high or low risk of obesity). In general, adherence to individual macronutrient dietary guidelines in isolation (i.e., independently of other guidelines) is likely to produce relatively small shifts in the distribution of obesity risk. This is because compliance with individual guidelines is not necessarily associated with significant reductions in excess calorie intakes. The high shares of fats and sugars in food energy intakes have been implicated as major factors responsible for the obesity "epidemic". However, our results suggest that compliance with fat and sugar guidelines may not lead to a large movement in the ECC distribution. The counterfactual decomposition exercise demonstrates that a large proportion of the population that complies with the guidelines continues to consume excessive calories. Compliance with the guidelines will not result in large changes in obesity risk, if as our analysis suggests, consumers are able to comply without significantly reducing calorie intake. In the case of proteins, the average 
share of energy derived from proteins is currently in excess of the guideline and is inversely related to ECC. Compliance with the guideline would call for a reduction in the share of energy derived from proteins and lead to an increase in ECC, increasing obesity risk. We recognise that compliance with individual macronutrient guidelines may have substantial health benefits related to the prevention of chronic disease - but compliance with individual guidelines in isolation may do little to address the problem of excess energy intake that drives obesity risk.

Adherence to guidelines for fruit and vegetable and fibre consumption (where the current average consumption falls below the recommended amount) may be associated with increased ECC, worsening obesity risk. Campaigns targeting fruit and vegetable consumption (e.g., provision of free fruit to school children to meet the five-a-day guideline) and fibre intake need to take into account these unintended consequences. The choice of the basket of foods through which compliance is achieved (their calorie content and the presence of other "unwanted" nutrients) is an important factor influencing ECC patterns. In the case of salt consumption, achievement of the guideline can have a large effect on ECC and consequently on obesity risk. It should be noted that the ECC reducing effects of compliance with the salt guideline may be (ironically) dampened by the efforts of the food industry to develop and market healthier product options (with lower salt content). This is because healthier option products make it easier for consumers to comply with the guideline without substantially reducing calorie consumption.

It is only simultaneous compliance with a set of dietary guidelines for nutrient intake that can potentially produce large shifts in the ECC distribution of the population. For combating the obesity risk of the population, public health measures will have to target combinations of dietary guidelines that are associated with the largest shifts in the ECC distribution. It is important to recognise that even when simultaneous compliance with all the recommended dietary guidelines is achieved, the ECC-reducing effects of compliance with certain guidelines may be (partially) offset by the ECC-increasing effects of compliance with other 
guidelines. The need for simultaneous compliance with dietary guidelines to have a significant effect on obesity risk may provide clues to resolve what is an apparent paradox in the nutrition data - the rising incidence of obesity over the last two decades even as consumers have been making healthier dietary choices and compliance with many of the recommended guidelines has been improving. We propose to explore the question of whether "returns" to healthy eating have been declining over time separately.

\section{Limitations of the Study}

We have noted earlier the limitations of the ECC measure derived from cross-sectional data in reflecting the cumulative consumption patterns of respondents. Nevertheless, a large nationally representative sample such as the NDNS does provide a reasonably robust approximation of the consumption patterns of the population as a whole for the purpose of assessing the shifts in the ECC distribution associated with conformity to dietary guidelines. This study also relies on reasonably accurate estimates of energy intake and energy expenditure to assess the magnitude of excess calorie consumption for individual respondents. Both self-reported energy intake and expenditure are known to be subject to systematic mis-reporting in large dietary surveys. Energy intake tends to be under-reported while energy expenditure tends to be over-reported, with the extent of mis-reporting varying across the BMI distribution. However, the model used in this study still offers a useful approach for overcoming the poor correlation between BMI and nutrient intakes in crosssectional studies. Dietary surveys such as the NDNS are now incorporating more reliable methods for estimating energy expenditure (e.g., doubly labelled water methods, measuring physical activity using triaxial accelerometers). As the reliability of data on energy intake and expenditure improves in dietary surveys, the model will produce more accurate results. The model remains useful in assessing the magnitude and direction of changes likely to result from better compliance with recommended dietary guidelines notwithstanding the difficulties in accurately assessing excess calorie consumption. 
We have estimated the magnitude of shifts in the ECC distribution of the population likely to be associated with conformity to only a subset of dietary guidelines, that is, those related to the nutrient composition of diets and the intake of individual nutrients. UK dietary guidelines include DRVs for energy intake as well. Dietary changes that achieve conformity to the DRVs for energy intake along with conformity to guidelines for nutrient intakes will be associated with much larger shifts in the ECC distribution than what we have estimated. However, many public health campaigns target compliance with specific nutrient guidelines in isolation. Our approach demonstrates that targeting compliance with individual nutrient guidelines can be expected to produce only modest shifts in the ECC distribution (and consequently in the distribution of obesity risk) of the population. We have, however, not examined the shifts in the ECC distribution that may arise if public health campaigns targeting nutrient intakes are combined with other fiscal or regulatory measures aimed at promoting healthier dietary choices.

The empirical model used in this paper does not establish a causal relationship between changes in the nutrient composition of diets and ECC. The changes in ECC associated with conformity to dietary guidelines arise on account of non-compliant diets being replaced with compliant diets. The changes in ECC associated with conformity are estimated on the basis of the observed diets in the population, which may change over time. Further, in our counterfactual decomposition exercise, we have focused on the shifts in the ECC distribution for the population as a whole as a result of compliance. We have not examined how the shifts in the ECC distribution may differ by gender or socio-demographic characteristics. The conditional QR results, however, provide an indication of how the ECC response to improved conformity to dietary guidelines is likely to vary across socio-demographic groups. The counterfactual decomposition exercise could have provided richer insights into the link between dietary changes and obesity risk if it could have been applied to two comparable NDNS surveys separated by one or two decades. That would have allowed the effect of dietary changes to be decomposed into co-efficient and covariate effects over this time period. Such an exercise was not feasible because, of the three dietary surveys considered in 
this paper (for 1986-87, 2000-2001 and 2008-2009), only the NDNS 2000-01 has data on physical activity. A counterfactual decomposition exercise based on a single dietary survey does not allow us to incorporate the effect of changes in dietary patterns that may have taken place after the survey. It may be feasible to undertake such an exercise if the rolling NDNS 2008-2009 survey were to release data on physical activity.

\section{Conclusions}

The promotion of healthier dietary choices and adherence to recommended dietary guidelines are important elements of the UK Government's efforts to combat the rising incidence of obesity. A range of public health campaigns and initiatives to promote healthy eating are aimed at achieving compliance with individual dietary guidelines. These may be undertaken by different agencies and may involve separate campaigns focusing exclusively on particular elements of healthy eating guidelines. Our results suggest that conformity with individual dietary guidelines, even if successfully achieved, is likely to be associated with relatively small shifts in the emerging distribution of obesity risk in the population. For segments of the population in the highest ECC quantiles (hence most prone to obesity), conformity to individual dietary guidelines may do little to reduce the risk of obesity. Combating the risk of obesity in these segments may call for different public health messages more centrally focused on energy balance. More generally, in order to have significant impact on the risk of obesity, public health campaigns and other initiatives promoting healthy eating need to adopt a more co-ordinated approach focusing on simultaneous compliance with a range of dietary guidelines. Measures promoting compliance with nutrient intake guidelines will not translate into truly healthier dietary choices unless they explicitly consider the unintended consequences of compliance on excessive energy intakes. 


\section{References}

Andryeva, T., Kelly, I.R., Harris, J.L., 2011.Exposure to food advertising on television: Association with children's fast food and soft drink consumption and obesity. Economics and Human Biology 9, 221-233.

Apovian, C.M., 2004. Sugar-sweetened soft drinks, obesity, and type 2 diabetes. J AMA: the J ournal of the American Medical Association 292, 978.

Astrup, A., 2001. The role of dietary fat in the prevention and treatment of obesity. Efficacy and safety of low-fat diets. International J ournal of Obesity Supplement, 25, S46-S50.

Astrup, A., 2005. The satiating power of protein-a key to obesity prevention? The American J ournal of Clinical Nutrition 82, 1.

Bates, B., Lennox, A., Swan, G., 2010. National Diet and Nutrition Survey: headline results from year 1 of the Rolling Programme (2008/2009). Food Standards Agency \& Department of Health, London.

Berkey, C.S., Rockett, H.R.H., Field, A.E., Gillman, M.W., Colditz, G.A., 2004. SugarAdded Beverages and Adolescent Weight Change. Obesity 12, 778-788.

Bolton-Smith, C., Woodward, M., 1994. Dietary composition and fat to sugar ratios in relation to obesity. International J ournal of Obesity 18, 820-828.

Boukouvalas, G., Shankar, B., Bruce Traill, W., 2009. Determinants of fruit and vegetable intake in England: a re-examination based on quantile regression. Public Health Nutrition 12, 2183-2191.

Bray, G.A., Popkin, B.M., 1998. Dietary fat intake does affect obesity! The American J ournal of Clinical Nutrition 68, 1157.

Burton-Freeman, B., 2000. Dietary fiber and energy regulation. The J ournal of Nutrition 130, 272.

Chou, S.Y., Grossman, M., Saffer, H., 2004. An economic analysis of adult obesity: results from the Behavioral Risk Factor Surveillance System. J ournal of Health Economics 23, 565- 587.

Department of Health, 1991. Dietary Reference Values of Food Energy and Nutrients for the United Kingdom. Report on Health \& Social Subjects 41. Report of the Panel on Dietary Reference Values of the Committee on Medical Aspects of Food Policy, TSO, UK.

European Commission, 2012. Implementation of the EU Salt Reduction Framework Results of Member States survey. Publications Office of the European Union, Luxembourg.

Frankenfield, D., Roth-Yousey, L., Compher, C., 2005. Comparison of predictive equations for resting metabolic rate in healthy non-obese and obese adults: a systematic review. J ournal of the American Dietetic Association 105, 775-789.

Gillis, L.J ., Bar-Or, O., 2003. Food away from home, sugar-sweetened drink consumption and juvenile obesity. J ournal of the American College of Nutrition 22, 539. 
Golay, A., Bobbioni, E., 1997. The role of dietary fat in obesity. International J ournal of Obesity, Supplement, 21, S2-S11.

Guenther, P.M., J uan, W.Y., Reedy, J ., Britten, P., Lino, M., Carlson, A., Hiza, H.H., Krebs-Smith, S.M. 2008. Diet Quality of Americans in 1994-96 and 2001-02 as Measured by the Healthy Eating Index-2005.Center for Nurition Policy and Promotion, Nutrition Insight 37, Aug.

Hill, J .O., Melanson, E.L.,Wyatt, H.T., 2000. Dietary fat intake and regulation of energy balance: implications for obesity. The J ournal of Nutrition 130, 284.

Hill, J .O., Peters, J .C., 1998. Environmental contributions to the obesity epidemic. Science 280, 1371.

Hofsteenge, G., Chinapaw, M., Delemarre-van de Waal, H.,Weijs, P., 2010. Validation of predictive equations for resting energy expenditure in obese adolescents. American J ournal of Clinical Nutrition 91, 1244.

J arvis, A., 2008. Food Matters - Toward A Strategy for the 21 st Century. Cabinet Office Report, Crown Copyright, London.

J ebb, S., 2007. Dietary determinants of obesity. Obesity Reviews 8, 93-97.

Koenker, R., 2005. Quantile Regression. Cambridge University Press.

Komlos, J ., Brabec, I., 2011. The trend of BMI values of US adults by deciles, birth cohorts 1882-1986 stratified by gender and ethnicity. Economics and Human Biology 9, 234-250.

Leidy, H.J ., Carnell, N.S., Mattes, R.D., Campbell, W.W., 2007. Higher Protein Intake Preserves Lean Mass and Satiety with Weight Loss in Pre-obese and Obese Women. Obesity 15, 421-429.

Lissner, L., Heitmann, B.L., 1995. Dietary fat and obesity: evidence from epidemiology. European J ournal of Clinical Nutrition 49, 79.

Ludwig, D.S., Peterson, K.E., Gortmaker, S.L., 2001. Relation between consumption of sugar-sweetened drinks and childhood obesity: a prospective, observational analysis. The Lancet 357, 505-508.

Machado, J ., Mata, J ., 2005. Counterfactual decomposition of changes in wage distributions using quantile regression. J ournal of Applied Econometrics 20, 445-465.

Merchant, A.T., Anand, S.S, Vuksan, V, J acobs, R., Davis, B., Teo,K., Yusuf, S., 2005. Protein intake is inversely associated with abdominal obesity in a multi-ethnic population. The J ournal of Nutrition 135, 1196 - 1201.

OECD, 2012. OECD Obesity Update. OECD, Paris. Available from http:// www.oecd.org/ els/ healthpoliciesanddata/49716427.pdf

ONS, 2005. National Diet and Nutrition Survey: Adults Aged 19 to 64 Years, 20002001 [computer file] SN: 5140 Office for National Statistics, Social and Vital Statistics Division and Food Standards Agency,. Colchester, Essex: UK Data Archive [distributor]. 
OPCS, 1991. Dietary and Nutritional Survey of British Adults, 1986-1987 [computer file] SN: 2836, Office of Population Censuses and Surveys, Social Survey Division, Colchester, Essex: UK Data Archive [distributor].

Pellet, P.L., 1990. Food energy requirement in humans. American J ournal of Clinical Nutrition, 51, 711-722.

Pereira, M., 2006. The possible role of sugar-sweetened beverages in obesity etiology: a review of the evidence. International J ournal of Obesity 30, S28-S36.

Poppitt, S., Eckhardt, J ., McGonagle, J ., Murgatroyd, P.,Prentice, A., 1996. Short-term effects of alcohol consumption on appetite and energy intake. Physiology and Behavior $60,1063-1070$.

Rennie, K., Coward, A., J ebb, S., 2007. Estimating under-reporting of energy intake in dietary surveys using an individualised method. British J ournal of Nutrition 97, 11691176.

Rosenheck, R., 2008. Fast food consumption and increased caloric intake: a systematic review of a trajectory towards weight gain and obesity risk. Obesity Reviews 9, 535-547.

Rzewnicki, R., Auweele, Y.V., De Bourdeaudhuij, I., 2003. Addressing over-reporting on the International Physical Activity Questionnaire (IPAQ) telephone survey with a population sample. Public Health Nutrition 6, 299-306.

Salois, M.J., 2012, Obesity and diabetes, the built environment, and the local' food economy in the United States, 2007. Economics and Human Biology 10, 35-42.

Sandy, R, Tchernis, R., Wilson, J., Liu, G., Zhou, X., 2012. Effects of the built environment on childhood obesity: the case of urban recreational trails and crime. Economics and Human Biology 11, 18-29..

Scientific Advisory Committee on Nutrition, 2011. Dietary Reference Values for Energy, TSO, London.

Sinha K., 2006. Household characteristics and calorie intake in rural India: a quantile regression approach. [WWW document]

URL: http:/ / dspace.anu.edu.au/ bitstream/ 1885/43190/ 1/WP2005 02.pdf

Smith, T.G., Stoddard, C., Barnes, M.G., 2009. Why the poor get fat: weight gain and economic insecurity. Forum for Health Economics and Policy 12.

Stubbs, J ., Ferres, S., Horgan, G., 2000. Energy density of foods: effects on energy intake. Critical Reviews in Food Science and Nutrition 40, 481-515.

Tohill, B.C., Seymour, J., Serdula, M., Kettel-Khan, L., Rolls, B.J ., 2004. What epidemiologic studies tell us about the relationship between fruit and vegetable consumption and body weight. Nutrition Reviews 62, 365-374.

Ulijaszek, S.J ., 2007. Frameworks of population obesity and the use of cultural consensus in the study of environments contributing to obesity. Economics and Human Biology 5, 443-457. 
US Department of Agriculture, 2010. Healthy Eating Index- 2005. Development and Evaluation Technical Support Files, 2010, Center for Nutrition Policy and Promotion.

US Department of Agriculture and US Department of Health and Human Services, 2010. Dietary Guidelines for Americans, 2010. $7^{\text {th }}$ Edition, U.S. Government Printing Office, Washington, DC.

US Department of Health and Human Services and US Department of Agriculture. Dietary Guidelines for Americans, 2005. 6th Edition, U.S. Government Printing Office, Washington, DC.

Variyam, J ., Blaylock, J., Smallwood, D., 2002. Characterizing the distribution of macronutrient intake among US adults: a quantile regression approach. American J ournal of Agricultural Economics 84, 454-466.

Volpe, R., Okrent, A., 2012. Assessing the Healthfulness of Consumers' Grocery Purchases. Economic Information Bulletin-102, US Department of Agriculture, Economic Research Service, November 2012.

Wack, J ., Rodin, J ., 1982 Smoking and its effects on body weight and the systems of caloric regulation. American J ournal of Clinical Nutrition 35, 366.

Warnecke, R.B., J ohnson, T.P., Chávez, N., Sudman, S., O'Rourke, D.P., Lacey, L., et al., 1997. Improving question wording in surveys of culturally diverse populations. Annals of Epidemiology 7, 334-342.

Wehby, G.L., Murray, J .C., Wilcox, A., Lie, R.T., 2012. Smoking and body weight: Evidence using genetic instruments. Economics and Human Biology 10, 113- 126.

Westerterp-Plantenga, M., Lejeune, M., Nijs, I., Van Ooijen, M., Kovacs, E., 2004. High protein intake sustains weight maintenance after body weight loss in humans. International J ournal of Obesity 28, 57-64.

Whybrow, S., Harrison, C.L.S., Mayer, C., Stubbs, R.J ., 2006. Effects of added fruits and vegetables on dietary intakes and body weight in Scottish adults. British J ournal of Nutrition 95, 496-503.

Willett, W., 2002. Dietary fat plays a major role in obesity: no. Obesity Reviews 3, 5968.

Willett, W.C., 1998a. Dietary fat and obesity: an unconvincing relation. The American J ournal of Clinical Nutrition 68, 1149.

Willett, W.C., 1998b. Is dietary fat a major determinant of body fat? The American J ournal of Clinical Nutrition 67, 556S.

Windham, C., Wyse, B., Hansen, R., 1983. Alcohol consumption and nutrient density of diets in the Nationwide Food Consumption Survey. J ournal of the American Dietetic Association 82, 364.

World Health Organization, 2003. Diet, Nutrition and the Prevention of Chronic Diseases. Report of a J oint WHO/ FAO Expert Consultation. WHO Technical Report Series no. 916. WHO, Geneva. 
World Health Organization, 2001. Human Energy Requirements. Report of a J oint FAO/WHO/UNU Expert Consultation, Rome, 17-24 October 2001. WHO, Geneva.

Yeomans, M., 2004. Effects of alcohol on food and energy intake in human subjects: evidence for passive and active over-consumption of energy. British J ournal of Nutrition 92, 31-34. 
Table-1: Trends in BMI Distribution of UK Adults

BMI (Kilogram/metre²)

\begin{tabular}{|c|c|c|c|c|c|c|c|}
\hline & 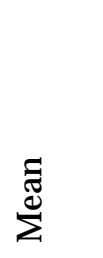 & 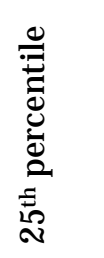 & 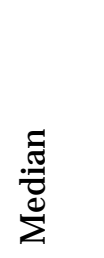 & 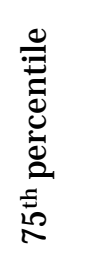 & 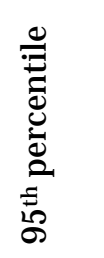 & $\begin{array}{l}\text { Proportion } \\
\text { of } \\
\text { overweight } \\
\text { adults } \\
(\text { BMI } \geq 25 \\
\text { and }<30)\end{array}$ & $\begin{array}{c}\text { Proportion } \\
\text { of obese } \\
\text { adults } \\
(\mathrm{BMI} \geq 30)\end{array}$ \\
\hline $1986-87^{a}$ & 24.7 & 21.8 & 24.1 & 26.7 & 32.5 & $40 \%$ & $10 \%$ \\
\hline $2000-01^{b}$ & 26.9 & 23.3 & 26.2 & 29.4 & 36.0 & $61 \%$ & $22 \%$ \\
\hline 2008-09c & 27.4 & 23.3 & 26.6 & 30.1 & 37.5 & $62 \%$ & $27 \%$ \\
\hline
\end{tabular}

${ }^{a}$ Computed from the Diet and Nutrition Survey of British Adults -1986-87 (OPCS, 1991)

b Computed from the National Diet and Nutrition Survey 2000-01(ONS, 2005)

c Computed from the National Diet and Nutrition Survey 2008-09 (Bates, Lennox and Swan, 2010) 


\begin{tabular}{ll}
\hline UKDietary Guidelines & \\
\hline Macronutrients & $\begin{array}{l}\text { Recommended amount } \\
\text { (\%o of total calorie intake) }\end{array}$ \\
Share of energy from: & $<33 \%$ \\
Total fat & $10 \%$ \\
Saturated fatty acids (SFAs) & \\
Monounsaturated fatty acids (MUFAs) & $12 \%$ \\
Polyunsaturated fatty acids (PUFAs) & $6-10 \%$ \\
Trans fatty acids (TFAs) & $<2 \%$ \\
Glycerol & $3 \%$ \\
Protein & $10-15 \%$ \\
Free Sugars & $<10 \%$ \\
Total carbohydrates & $50 \%$ \\
& \\
Other nutrients/ foods & $\begin{array}{l}\text { Recommended amount } \\
\text { (daily consumption) }\end{array}$ \\
Cholesterol & $<300 \mathrm{mg} /$ day \\
Fruit and Vegetables & $>=400 \mathrm{gms}$ per day \\
Salt & $<6$ gms/day \\
Sodium equivalent & $<2.36 \mathrm{gms} /$ day \\
Total dietary fibre & $>=18 \mathrm{gms} /$ day
\end{tabular}

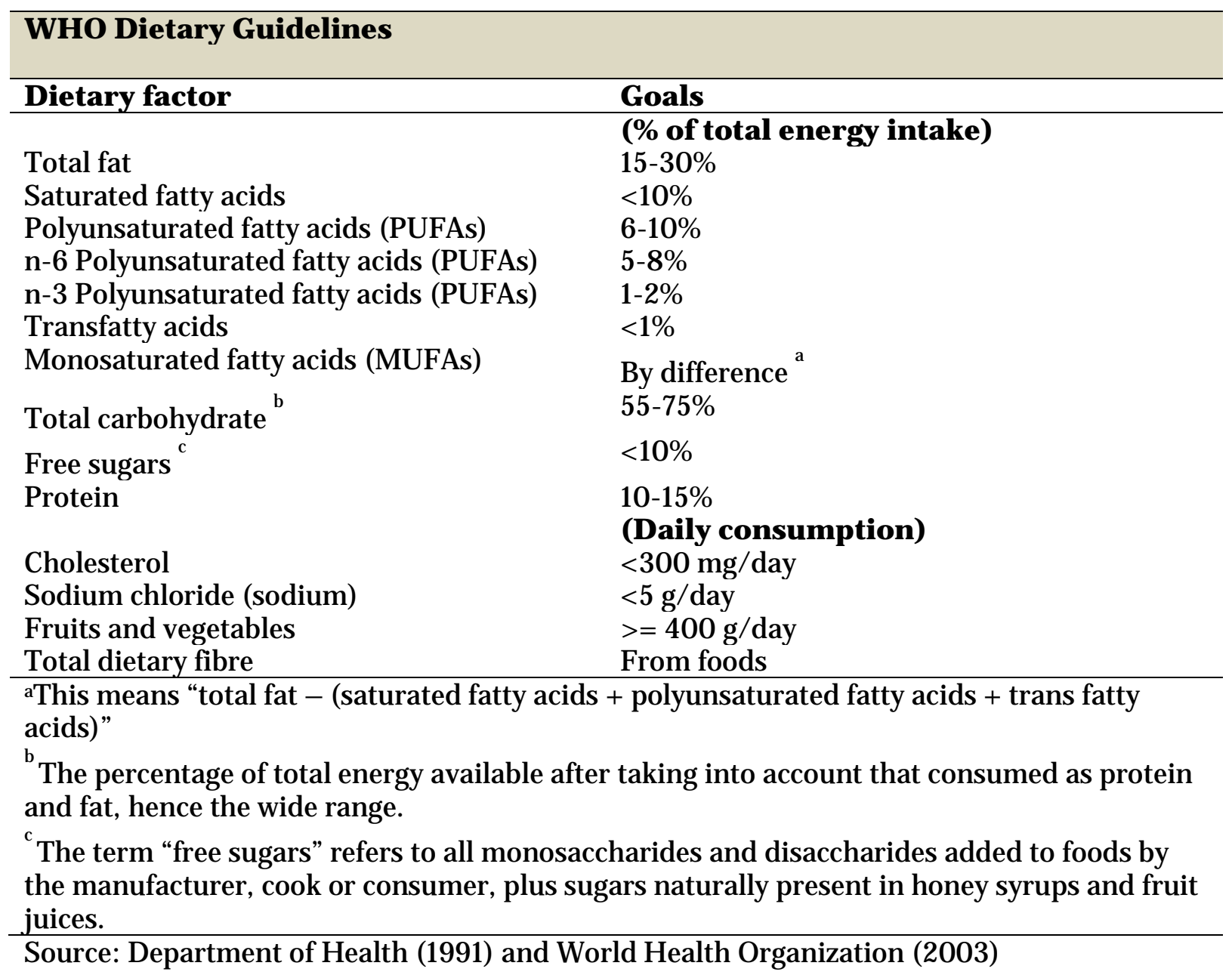




\begin{tabular}{|c|c|c|c|c|c|c|c|}
\hline & Yeara & 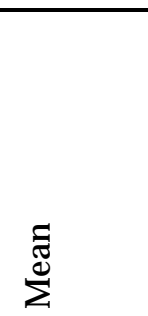 & 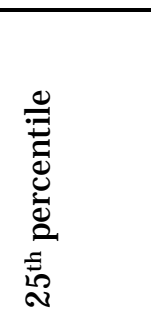 & : & 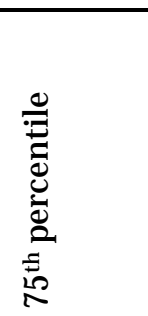 & 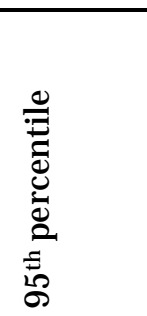 & $\begin{array}{l}\text { Non- } \\
\text { conforming } \\
\text { UK adults } \\
\quad(\%)\end{array}$ \\
\hline \multicolumn{8}{|l|}{$\begin{array}{l}\text { Share of food } \\
\text { energy (\%) from }\end{array}$} \\
\hline \multirow[t]{3}{*}{ All fats } & $1986-87$ & 40.4 & 37.4 & 40.5 & 43.6 & 47.9 & 93.1 \\
\hline & $2000-01$ & 35.4 & 31.5 & 35.6 & 39.4 & 44.9 & 67.6 \\
\hline & 2008-09 & 34.8 & 31.2 & 35.1 & 38.5 & 43.1 & 64.7 \\
\hline \multirow[t]{3}{*}{ Saturated fats } & $1986-87$ & 16.8 & 14.7 & 16.7 & 18.8 & 21.9 & 98.4 \\
\hline & 2000-01 & 13.3 & 11.3 & 13.3 & 15.2 & 18.4 & 85.0 \\
\hline & 2008-09 & 13.2 & 11.2 & 13.1 & 15.1 & 18.4 & 86.6 \\
\hline \multirow{3}{*}{$\begin{array}{l}\text { Poly- } \\
\text { unsaturated fats }\end{array}$} & 1986-87 & 6.1 & 4.6 & 5.7 & 7.3 & 10.1 & 5.2 \\
\hline & 2000-01 & 6.3 & 5.1 & 6.2 & 7.3 & 9.4 & 2.6 \\
\hline & 2008-09 & 5.2 & 4.6 & 5.7 & 6.8 & 8.7 & 1.9 \\
\hline \multirow{3}{*}{$\begin{array}{l}\text { Mono- saturated } \\
\text { fats }\end{array}$} & 1986-87 & 12.3 & 11.0 & 12.3 & 13.5 & 15.7 & 54.0 \\
\hline & 2000-01 & 11.8 & 10.2 & 11.8 & 13.4 & 15.7 & 45.2 \\
\hline & 2008-09 & 12.3 & 10.7 & 12.3 & 14.0 & 16.4 & 55.6 \\
\hline \multirow{3}{*}{$\begin{array}{l}\text { Non-milk } \\
\text { extrinsic sugars }\end{array}$} & $1986-87^{b}$ & 19.3 & 15.0 & 19.1 & 23.3 & 29.6 & 69.9 \\
\hline & 2000-01 & 12.8 & 8.3 & 11.7 & 12.8 & 16.0 & 62.5 \\
\hline & 2008-09 & 13.5 & 8.9 & 12.6 & 17.0 & 25.2 & 69.5 \\
\hline \multirow[t]{3}{*}{ Protein } & 1986-87 & 14.5 & 12.6 & 14.2 & 16.1 & 20.3 & 36.7 \\
\hline & $2000-01$ & 16.5 & 14.3 & 16.1 & 18.3 & 22.5 & 64.8 \\
\hline & 2008-09 & 15.9 & 13.6 & 15.4 & 17.7 & 21.9 & 55.7 \\
\hline \multicolumn{8}{|l|}{ Consumption of } \\
\hline \multirow{3}{*}{$\begin{array}{l}\text { Fruit and } \\
\text { Vegetables } \\
\text { (gms) }\end{array}$} & $1986-87$ & 216.6 & - & - & - & - & - \\
\hline & 2000-01 & 276.8 & 133.6 & 231.6 & 382.3 & 647.7 & 77.6 \\
\hline & 2008-09 & 300.6 & 175.6 & 273.7 & 395.3 & 610.3 & 75.8 \\
\hline \multirow{3}{*}{$\begin{array}{l}\text { Fibre } \\
\text { (gms) }\end{array}$} & 1986-87 & 21.7 & 15.8 & 20.6 & 26.3 & 36.5 & 66.4 \\
\hline & $2000-01^{c}$ & 13.0 & 9.0 & 12.0 & 16.0 & 23.0 & 84.3 \\
\hline & $2008-09 c$ & 12.1 & 8.7 & 11.4 & 14.5 & 21.1 & 88.6 \\
\hline \multirow[t]{3}{*}{ Sodium (gms) } & 1986-87 & 2.9 & 2.2 & 2.7 & 3.4 & 4.7 & 66.9 \\
\hline & 2000-01 & 2.8 & 2.1 & 2.6 & 3.3 & 4.5 & 62.4 \\
\hline & 2008-09 & 2.1 & 1.5 & 2.0 & 2.6 & 3.7 & 34.3 \\
\hline \multirow{3}{*}{$\begin{array}{l}\text { Cholesterol } \\
\text { (mg) }\end{array}$} & 1986-87 & 334.1 & 235.4 & 313.1 & 410.0 & 590.2 & 53.9 \\
\hline & 2000-01 & 255.6 & 172.2 & 236.7 & 319.4 & 479.4 & 29.6 \\
\hline & 2008-09 & - & - & - & - & - & - \\
\hline \multicolumn{8}{|c|}{$\begin{array}{l}\text { a Figures computed from the Dietary and Nutrition Survey of British Adults 1986-87(OPCS, } \\
\text { 1991) and from the National Diet and Nutrition Surveys for 2000-01 (ONS, 2005) and 2008-09 } \\
\text { (Bates, Lennox and Swan, 2010). } \\
\text { b Figures for 1986-87 are for share of food energy derived from all sugars. } \\
\text { c Figures for 2000-01 and 2008-09 are based on the Englyst method. }\end{array}$} \\
\hline
\end{tabular}


Table-4: Variable Description

\begin{tabular}{|c|c|c|c|}
\hline Variable & Acronym & Units & $\begin{array}{l}\text { Mean } \\
(\mathrm{N}=1344)\end{array}$ \\
\hline \multicolumn{4}{|l|}{ Continuous variables } \\
\hline Food energy from saturated fats & satfat & $(\%)$ & 13.3 \\
\hline Food energy from polyunsaturated fats & pufat & (\%) & 6.3 \\
\hline Food energy from monounsaturated fats & monofat & (\%) & 11.8 \\
\hline Food energy from non-milk extrinsic sugars & sugar & (\%) & 12.8 \\
\hline Food energy from proteins & prot & $(\%)$ & 16.5 \\
\hline Food energy from starch & star & $(\%)$ & 27.3 \\
\hline Fruit and vegetable consumption per day & frveg & gms & 276.8 \\
\hline Fibre consumption per day & fibre & gms & 13.0 \\
\hline Sodium consumption per day & sodium & gms & 2.8 \\
\hline Cigarettes smoked per day & smoking & number & 4.6 \\
\hline Alcohol consumption per day & alcoh & gms & 15.5 \\
\hline Cholesterol consumption per day & chol & $\mathrm{mg}$ & 225.6 \\
\hline Average daily physical activity score & phyact & $\begin{array}{l}\text { Scores range } \\
\text { from } 33 \\
\text { (inactive) - } \\
100 \text { (very } \\
\text { highly active) }\end{array}$ & 43.9 \\
\hline Age of respondent & age & years & 42.1 \\
\hline Dummy variables & & & $\begin{array}{l}\text { Proportion } \\
\text { in sample }\end{array}$ \\
\hline $\begin{array}{l}\text { Gender of respondent } \\
\text { (Base category= Male) }\end{array}$ & female & & $52.9 \%$ \\
\hline \multirow[t]{3}{*}{$\begin{array}{l}\text { Race/ Ethnicity of respondent } \\
\text { (Base category= Whites) }\end{array}$} & $\begin{array}{l}\text { race-ethnic- } \\
\text { Asian }\end{array}$ & & $1.64 \%$ \\
\hline & $\begin{array}{l}\text { race-ethnic- } \\
\text { Black }\end{array}$ & & $1.64 \%$ \\
\hline & $\begin{array}{l}\text { race-ethnic- } \\
\text { Others }\end{array}$ & & $1.86 \%$ \\
\hline $\begin{array}{l}\text { Occupational category of respondent } \\
\text { (Base category= Non-manual) }\end{array}$ & manual & & $39.5 \%$ \\
\hline
\end{tabular}


Table-5: Determinants of Excess Calorie Consumption: OLS and Quantile Regression Results

\begin{tabular}{|c|c|c|c|c|c|c|c|c|c|c|c|c|}
\hline \multirow{3}{*}{ Variable } & \multirow{2}{*}{\multicolumn{2}{|c|}{ OLS }} & \multicolumn{10}{|c|}{ QUANTILE REGRESSION } \\
\hline & & & \multicolumn{2}{|c|}{$5^{\text {th }}$ quantile } & \multicolumn{2}{|c|}{$25^{\text {th }}$ quantile } & \multicolumn{2}{|c|}{$50^{\text {th }}$ quantile } & \multicolumn{2}{|c|}{$75^{\text {th }}$ quantile } & \multicolumn{2}{|c|}{$90^{\text {th }}$ quantile } \\
\hline & Coeff & p-val & Coeff & $\begin{array}{c}\mathrm{p}- \\
\text { val }\end{array}$ & Coeff & $\begin{array}{l}\mathrm{p}- \\
\text { val }\end{array}$ & Coeff & $\begin{array}{l}\mathrm{p}- \\
\text { val }\end{array}$ & Coeff & $\begin{array}{l}\mathrm{p}- \\
\text { val }\end{array}$ & Coeff & $\begin{array}{l}\mathrm{p}- \\
\text { val }\end{array}$ \\
\hline Intercept & $\mathbf{8 0 . 1 5}$ & 0.00 & $\mathbf{8 9 . 8 9}$ & 0.00 & $\mathbf{9 0 . 4 1}$ & 0.00 & 90.58 & 0.00 & 98.20 & 0.00 & 112.76 & 0.00 \\
\hline satfat & 0.67 & 0.02 & 0.65 & 0.19 & 0.55 & 0.05 & 0.70 & 0.01 & 0.92 & 0.01 & 0.41 & 0.26 \\
\hline pufat & 0.12 & 0.74 & -0.50 & 0.44 & -0.08 & 0.81 & 0.03 & 0.92 & 0.04 & 0.94 & -0.08 & 0.86 \\
\hline monofat & -0.81 & 0.01 & -1.14 & 0.09 & -0.70 & 0.03 & -0.18 & 0.56 & -0.30 & 0.48 & -0.47 & 0.32 \\
\hline sugar & 0.76 & 0.00 & 0.21 & 0.57 & 0.68 & 0.00 & 0.94 & 0.00 & 0.97 & 0.00 & 0.89 & 0.00 \\
\hline prot & -2.20 & 0.00 & -2.30 & 0.00 & -1.88 & 0.00 & -1.85 & 0.00 & -1.95 & 0.00 & -2.24 & 0.00 \\
\hline star & -0.17 & 0.40 & -0.59 & 0.11 & -0.19 & 0.34 & 0.01 & 0.96 & 0.07 & 0.80 & -0.22 & 0.35 \\
\hline frveg & 0.01 & 0.11 & 0.00 & 0.95 & 0.01 & 0.16 & 0.01 & 0.09 & 0.01 & 0.21 & 0.00 & 0.45 \\
\hline fibre & 1.38 & 0.00 & 1.04 & 0.00 & 1.38 & 0.00 & 1.47 & 0.00 & 1.69 & 0.00 & 1.83 & 0.00 \\
\hline sodium & 12.97 & 0.00 & 11.17 & 0.00 & 12.24 & 0.00 & 13.05 & 0.00 & 12.97 & 0.00 & 12.80 & 0.00 \\
\hline smoking & 0.09 & 0.12 & -0.15 & 0.29 & 0.07 & 0.32 & 0.10 & 0.15 & 0.11 & 0.13 & 0.16 & 0.22 \\
\hline alcoh & -0.20 & 0.00 & -0.10 & 0.09 & -0.14 & 0.00 & -0.20 & 0.00 & -0.21 & 0.00 & -0.24 & 0.00 \\
\hline chol & 0.08 & 0.00 & 0.07 & 0.00 & 0.08 & 0.00 & 0.07 & 0.00 & 0.07 & 0.00 & 0.09 & 0.00 \\
\hline phyact & -0.64 & 0.00 & -0.55 & 0.00 & -0.49 & 0.00 & -0.57 & 0.00 & -0.76 & 0.00 & -0.81 & 0.00 \\
\hline age & 0.31 & 0.00 & 0.19 & 0.03 & 0.26 & 0.00 & 0.33 & 0.00 & 0.39 & 0.00 & 0.34 & 0.00 \\
\hline female & -4.83 & 0.00 & -7.21 & 0.00 & -3.94 & 0.00 & -4.23 & 0.00 & -5.08 & 0.00 & -3.36 & 0.05 \\
\hline $\begin{array}{l}\text { race- } \\
\text { ethnic- } \\
\text { Asian }\end{array}$ & 8.55 & 0.02 & 12.34 & 0.00 & 11.48 & 0.00 & 8.75 & 0.00 & 6.47 & 0.02 & 2.89 & 0.11 \\
\hline $\begin{array}{l}\text { race- } \\
\text { ethnic- } \\
\text { Black }\end{array}$ & 3.76 & 0.31 & 5.79 & 0.09 & 5.12 & 0.18 & -0.42 & 0.86 & 6.05 & 0.02 & 0.29 & 0.89 \\
\hline $\begin{array}{l}\text { race- } \\
\text { ethnic- }\end{array}$ & 7.44 & 0.03 & 15.87 & 0.00 & 9.74 & 0.00 & 7.11 & 0.00 & 0.78 & 0.92 & 7.57 & 0.00 \\
\hline manual & -0.92 & 0.36 & -2.99 & 0.12 & -4.45 & 0.00 & -2.36 & 0.03 & 3.05 & 0.04 & 2.25 & 0.10 \\
\hline & $\mathrm{R}^{2}=0$ & & Pseuc & $2=0$ & $\mathrm{C}$ & cie & ign & nt a & or & era & bold. & \\
\hline
\end{tabular}




\begin{tabular}{|c|c|c|c|c|c|c|}
\hline \multicolumn{7}{|c|}{ Calories consumed as percent of need } \\
\hline & $\sum_{\substack{\mathbb{d} \\
\text { ¿ }}}$ & 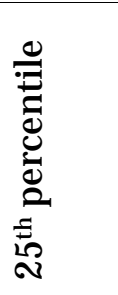 & : & 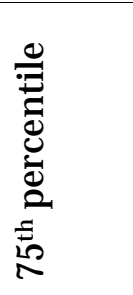 & 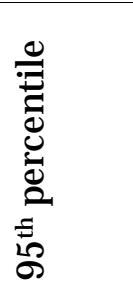 & $\begin{array}{c}\text { Adults not } \\
\text { consuming } \\
\text { excess calories } \\
(\%)\end{array}$ \\
\hline NDNS-2000-01 & 109.4 & 89.9 & 108.0 & 127.2 & 158.7 & 38.4 \\
\hline \multicolumn{7}{|c|}{ Effects of adherence to individual dietary guidelines } \\
\hline All fats & 104.1 & 84.9 & 102.8 & 121.1 & 154.1 & 46.0 \\
\hline Saturated fats & 99.6 & 79.1 & 98.2 & 116.7 & 152.7 & 52.5 \\
\hline PUFA & 110.7 & 90.2 & 108.1 & 128.6 & 162.4 & 37.9 \\
\hline Monosaturated fats & 107.7 & 89.7 & 105.9 & 124.3 & 156.1 & 41.0 \\
\hline $\begin{array}{l}\text { Non-milk extrinsic } \\
\text { sugars }\end{array}$ & 101.9 & 81.7 & 99.8 & 119.5 & 153.8 & 50.3 \\
\hline Protein & 118.5 & 99.1 & 116.7 & 134.2 & 169.5 & 26.3 \\
\hline Fruit and Vegetable & 122.4 & 102.8 & 120.2 & 139.6 & 175.8 & 21.4 \\
\hline Fibre & 134.7 & 115.3 & 131.6 & 152.1 & 185.3 & 8.3 \\
\hline Sodium & 88.8 & 73.1 & 88.8 & 103.5 & 126.7 & 70.0 \\
\hline Cholesterol & 99.6 & 83.6 & 98.7 & 115.1 & 140.9 & 52.2 \\
\hline
\end{tabular}

\section{Effects of adherence to a combination of guidelines}

Saturated fat and non-milk extrinsic sugars

$\begin{array}{lllll}92.7 & 71.1 & 90.0 & 107.9 & 153.7\end{array}$

65.0

Saturated fats, nonmilk extrinsic sugars and fruit and $\begin{array}{lllll}106.3 & 84.6 & 100.8 & 120.9 & 171.2\end{array}$ vegetables

Saturated fats, nonmilk extrinsic sugar and fibre

Saturated fats, non$\begin{array}{lllllll}\text { milk extrinsic sugars } & 76.8 & 62.4 & 74.1 & 90.9 & 114.1 & 85.7\end{array}$ and sodium

$\begin{array}{lllllll}\text { All dietary guidelines } & 76.2 & 62.0 & 73.9 & 90.0 & 113.5 & 85.0\end{array}$ 
Figure-1A: Conditional Quantile Effects of Nutrient Intake Variables by Excess Calorie Consumption(ECC) Quantiles

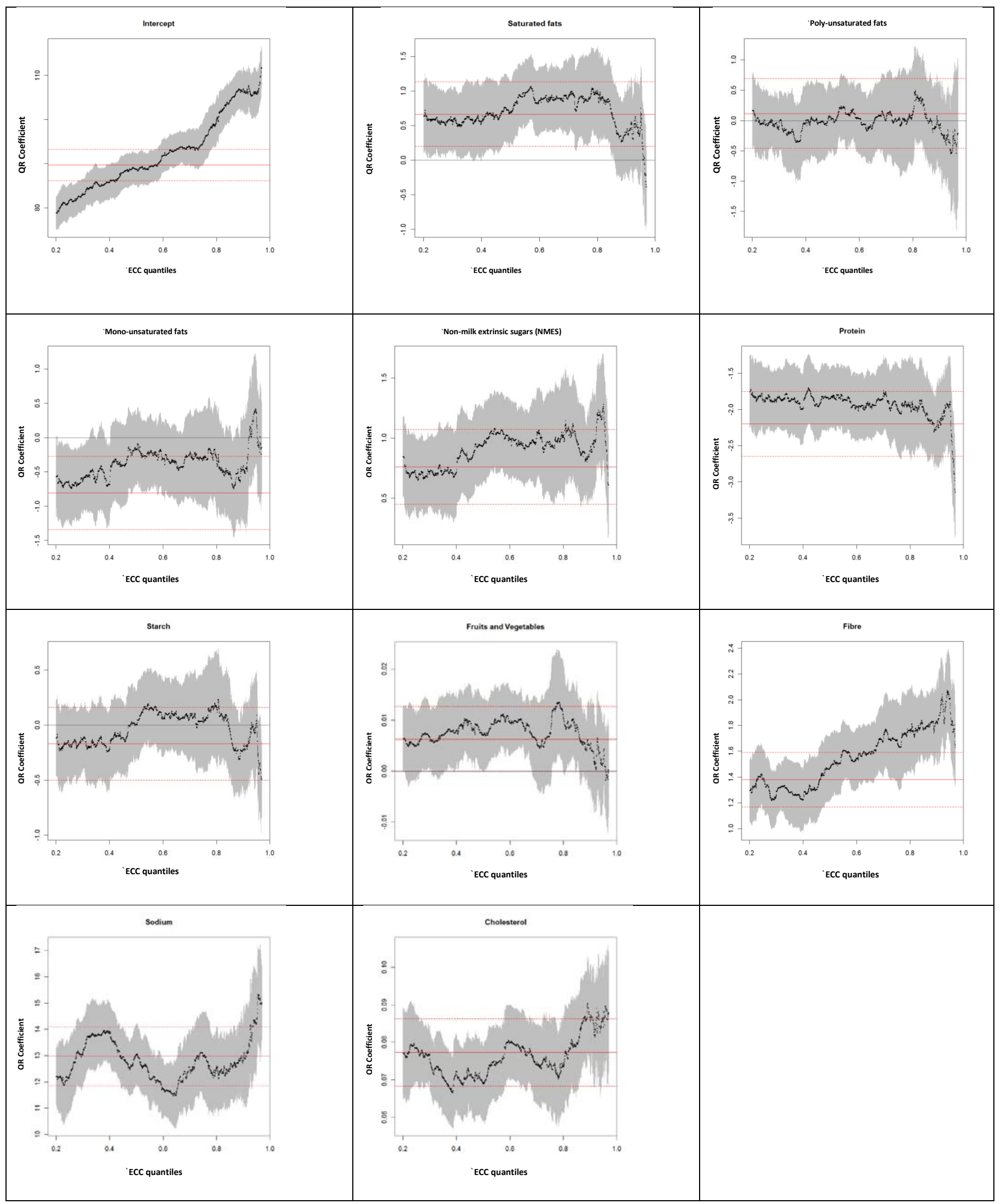

(Source: Table-5) 
Figure-1B: Conditional Quantile Effects of Lifestyle, Physical Activity and Demographic Factors by Excess Calorie Consumption (ECC) Quantiles

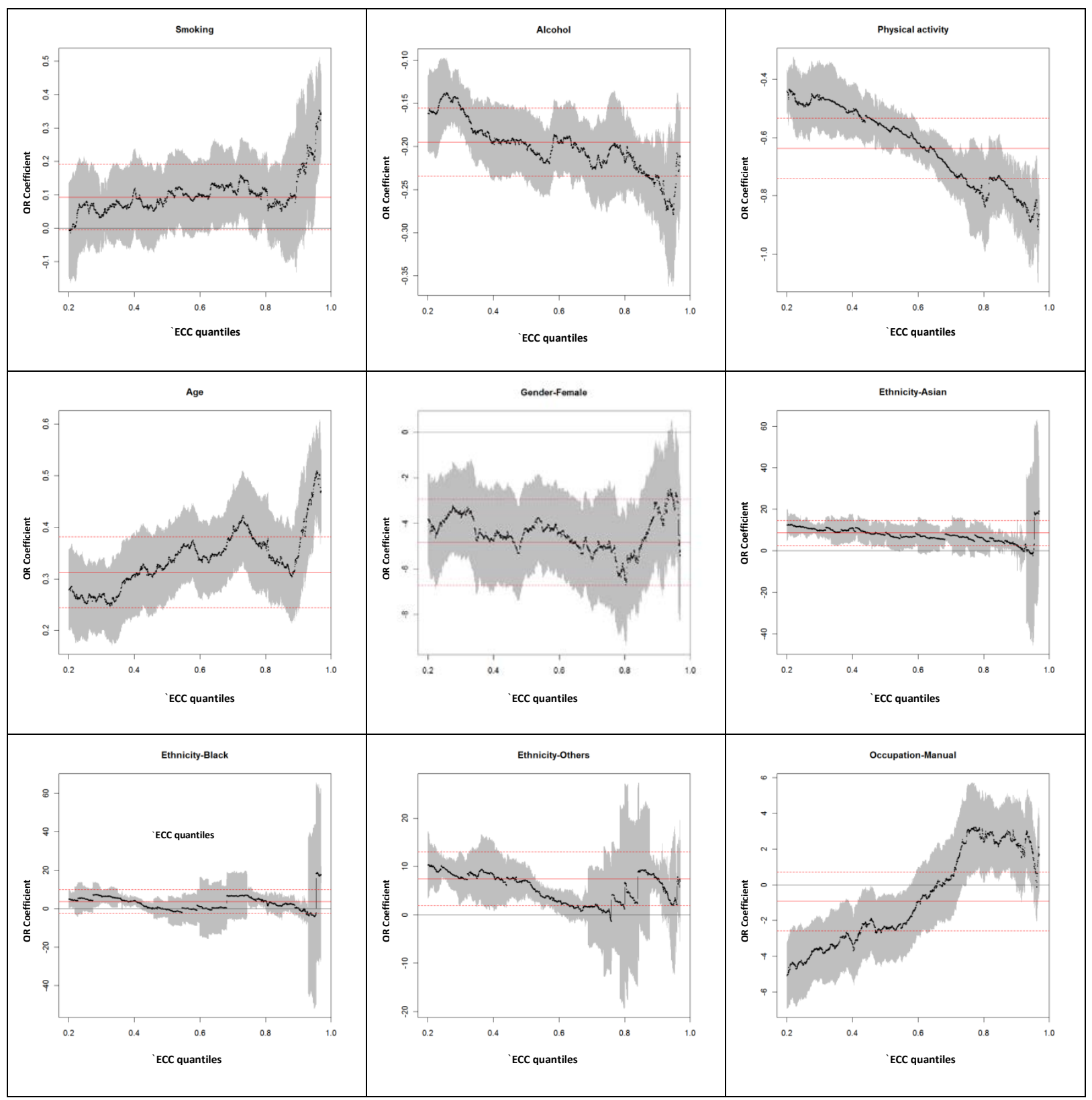

(Source: Table-5) 
Figure-2: Effects of Adherence to Individual Dietary Guidelines on Excess Calorie Consumption

All fats

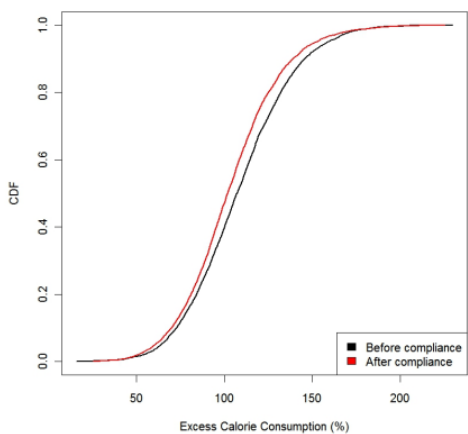

Mono-saturated fats

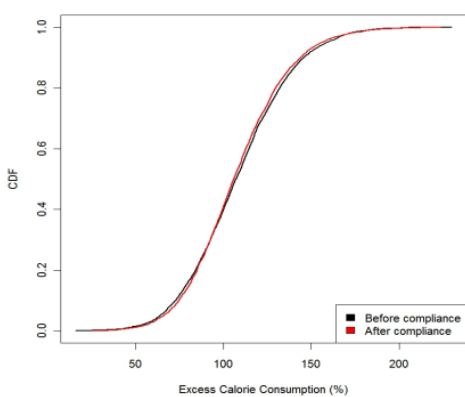

Fruit and Vegetables

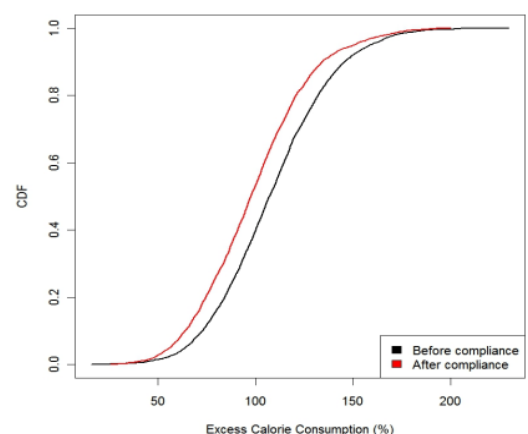

Non-Milk Extrinsic Sugars (NMES)

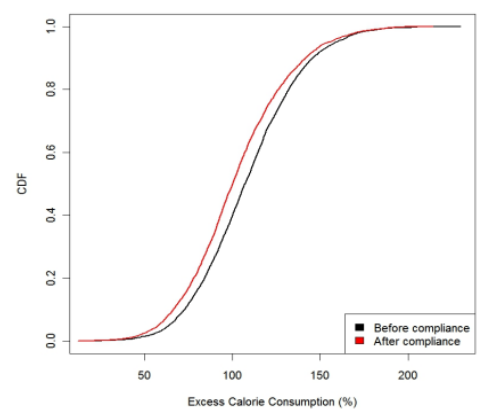

Poly-unsaturated fats

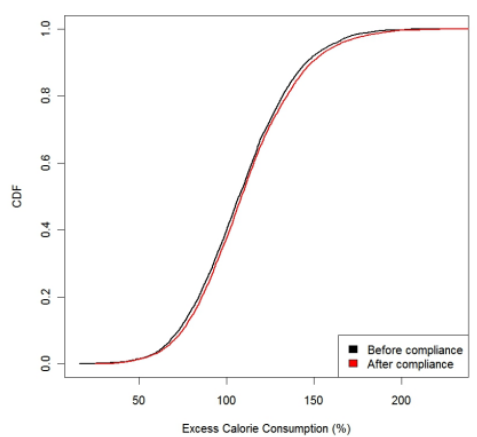

Protein

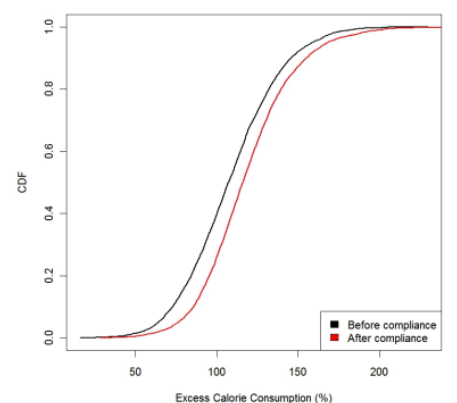

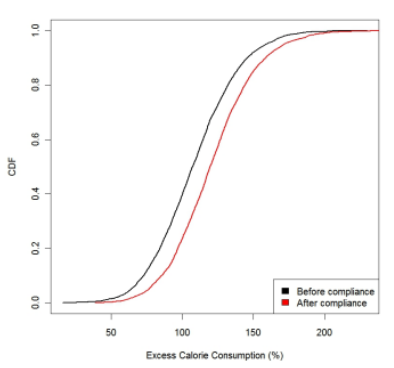
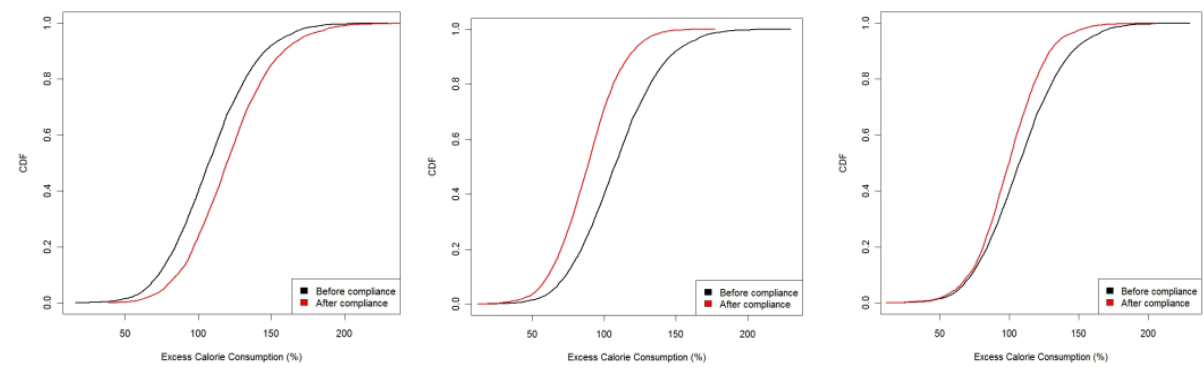
Figure-3: Effects of Adherence to Combinations of Dietary Guidelines on Excess Calorie Consumption

Saturated fats and NMES

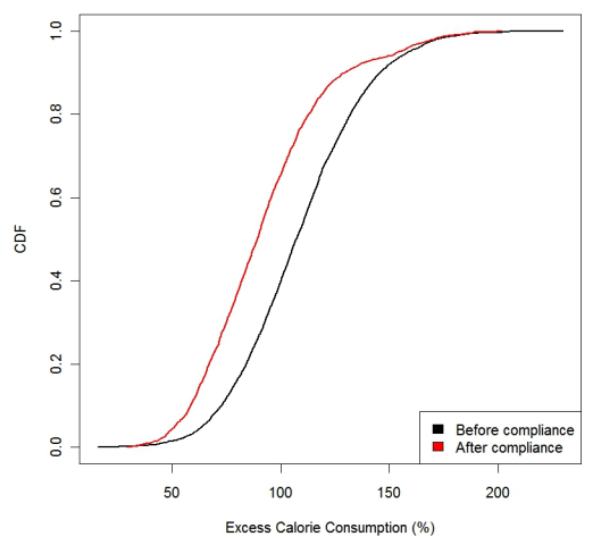

Saturated fats, NMES and Fibre

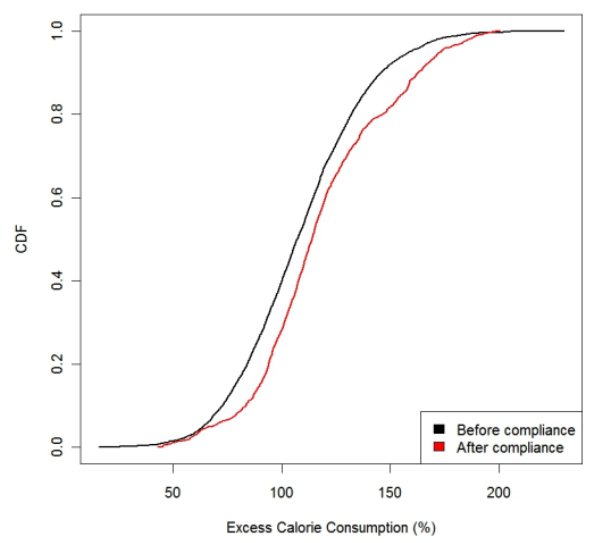

Saturated fats, NMES and Fruit and Vegetables

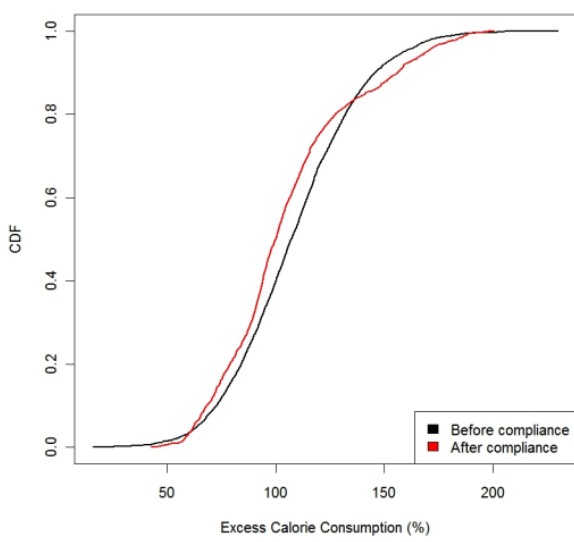

Saturated fats, NMES and Sodium

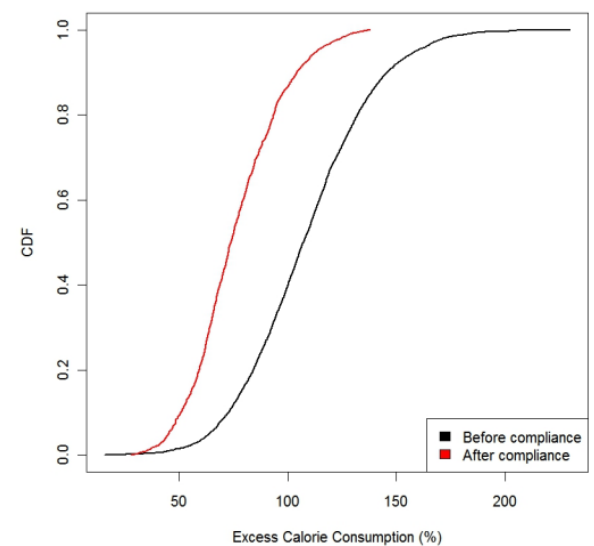

Dietary guidelines for all nutrients

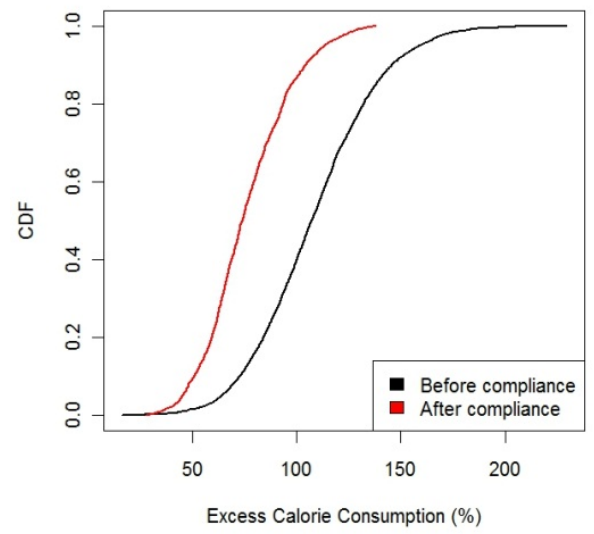

